\title{
Large-Span Timber Structures
}

\author{
Roberto Crocetti \\ Division of Structural Engineering, Lund University \\ P.O. Box 118, SE-221 00 Lund, Sweden \\ roberto.crocetti@kstr.lth.se
}

\begin{abstract}
Large spans structures should ideally be designed so that they work primarily in tension and/or compression. In fact, minimizing bending moments leads in general to an optimum utilisation of the structure, regardless what material is chosen. This often results in slender and elegant shapes.

Timber is a structural material which has excellent strength and stiffness, in particular when these properties are expressed in specific terms. By specific strength and specific stiffness, it is meant the material strength and the material Young's modulus, respectively, divided by its density. As an example, it can be mentioned that both the specific strength and the stiffness in tension and compression parallel to the grain of e.g. spruce timber are even superior to that of a common carbon steel. For this reason, timber is a material which is particularly appropriate for large span structures.

This paper gives a description of both traditional and innovative structural shapes which can be used for large buildinsg with timber as main load bearing material. Emphasis is put on planar structures; however, a brief discussion on spatial structures will also be presented.

As spans become longer, a number of problems arises. For example, as compression members get longer, buckling begins to be an issue. Moreover, most likely large-span structures will be made of several members, which must be prevented from coming apart at the joints. In this paper, methods to reduce the risk for both in-plane and out-of-plane buckling of timber members are illustrated. Also, suitable joints able to resist either large compression and tension forces are presented and discussed.
\end{abstract}

\section{Historical Background}

Conceivably, bridges are the first examples of man-made large-span timber structures. The need of overcoming obstacles such as rivers or valleys, has always challenged the humans to find suitable structures that could span over considerable distances. Until the first half of the nineteenth century, wood was basically the only material available for such a purpose. Especially after the sixteenth century, bridges of considerable engineering interest were executed using wood. Among the most eminent examples of this type of structures, built between the sixteenth and nineteenth century, the following bridges can be mentioned:

- The bridges of Andrea Palladio (XVI century), the great architect/engineer of the Italian Renaissance. One of his most representative examples is the bridge of Bassano del Grappa, later renamed "Ponte degli Alpini" [1], see Figure 1.

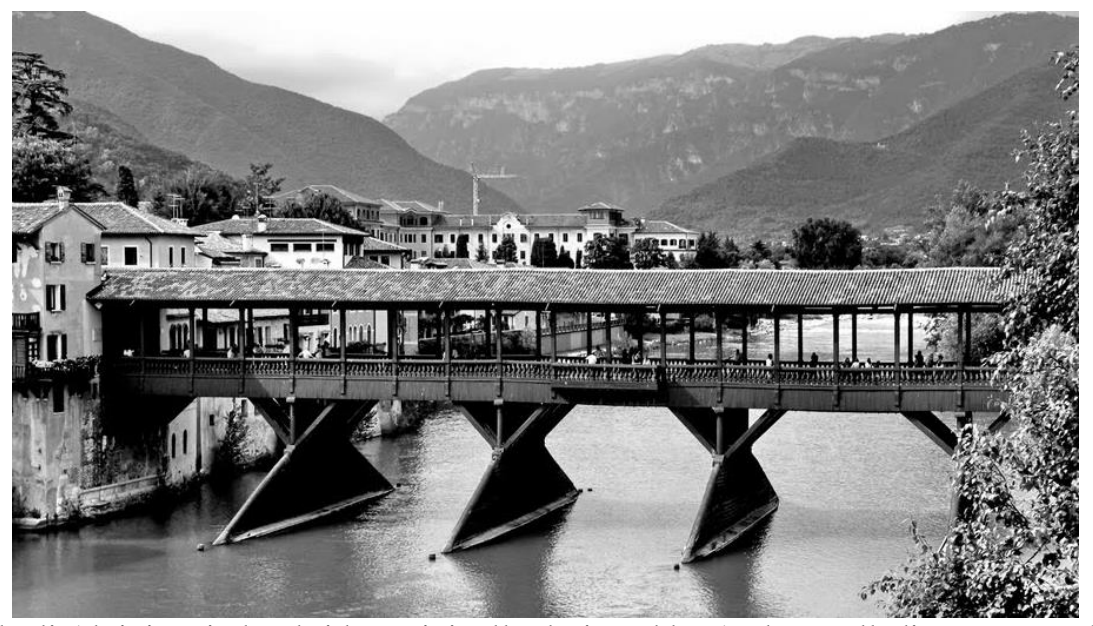

Fig. 1: Ponte degli Alpini, a timber bridge originally designed by Andrea Palladio, Bassano del Grappa, IT. 
- The works of two talented Swiss carpenters, the brothers Johannes and Hans-Ulrich Grubenmann (XVIII century), who built wooden bridges with spans never seen before. One of their most famous masterwork is the bridge over the Rhine River in Schaffhausen built 1755 - 1758, Switzerland, Length: 120m, in two spans [1], see the model in see Figure 2.

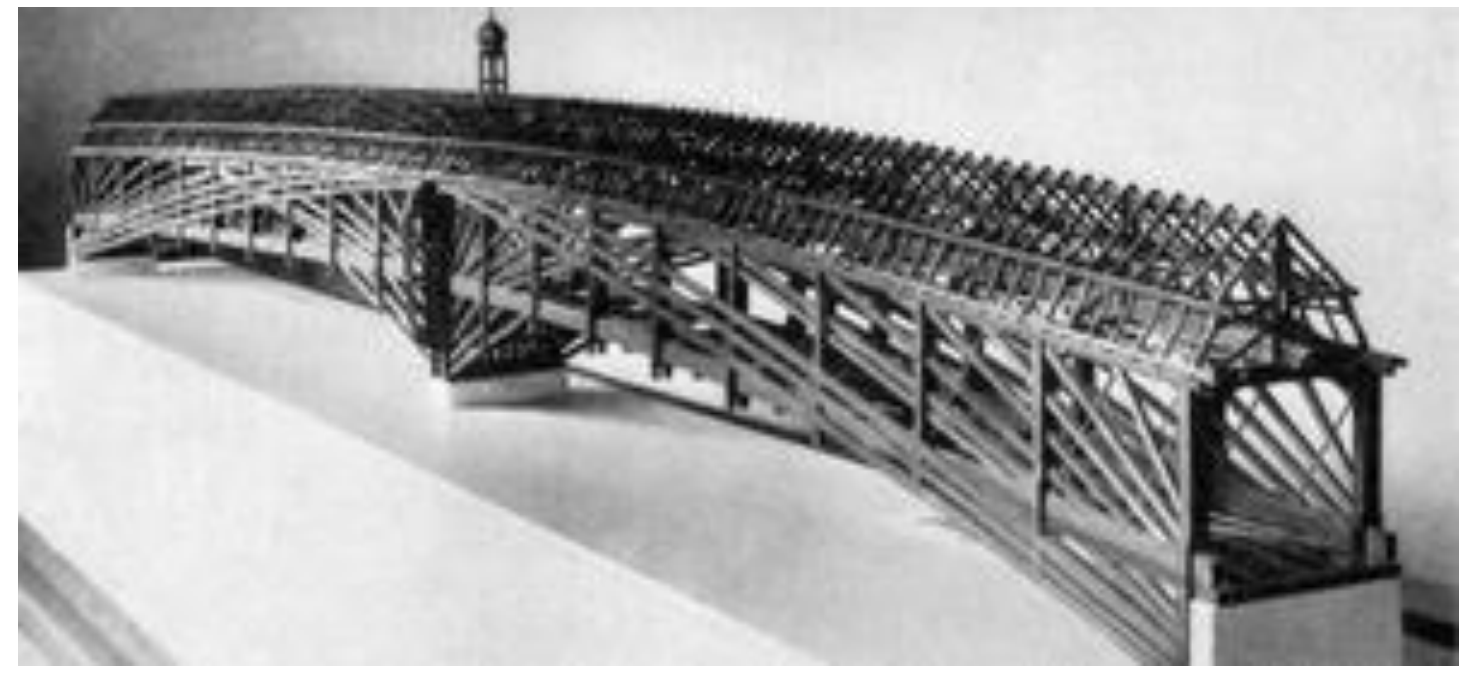

Fig. 2: Model of the main structural members of the timber bridge over the Rhine river e in Schaffhausen, Switzerland.

- The impressive Colossus bridge, designed and built by the German Lewis Wernwag, a prominent bridge builder who worked in the United States in the early 19th century. The Colossus Bridge - formally known as the Lancaster Schuylkill Bridge - was a record-setting timber bridge across the Schuylkill River near Philadelphia. It was built in 1812 and it had a clear span of approximately $104 \mathrm{~m}$ which far exceeded any bridge of its time. The deck width was variable with two carriageways and two sidewalks. The load-carrying structure consisted of four trussed timber arches. The trusses also included some iron diagonal members and from the structural point of view they behaved very similarly to hingeless arches. The overall width was approximately $10 \mathrm{~m}$ at mid-span and $15.2 \mathrm{~m}$ at the abutment. The rise of the lower chord was approximately $6.1 \mathrm{~m}$ [2]. See Figure 3.

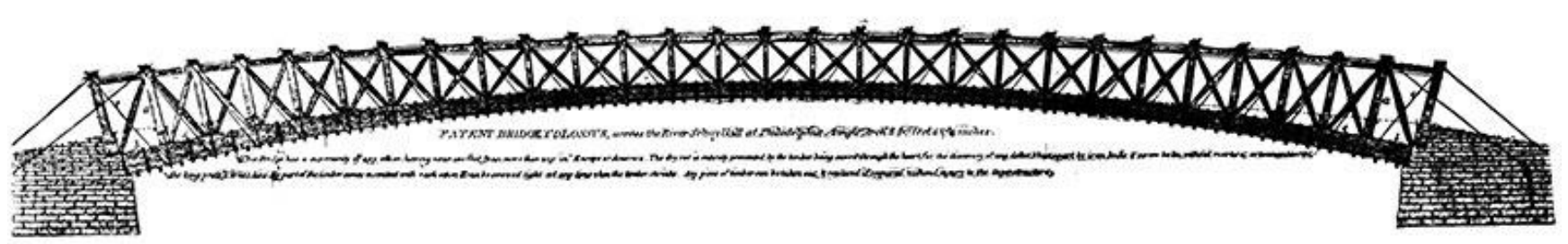

Fig. 3: Wernwag's Colossus timber bridge over the Schuylkill River near Philadelphia, USA, 1812. Elevation view.

- The spectacular railway bridges by Isambard Kingdom Brunel (XIX century), one of the greatest British engineers of all times. One of Brunel's most known timber bridge is the railway viaduct at Moorswater, Great Britain, total length 290 m, height: 45 m [1], see Figure 4. 


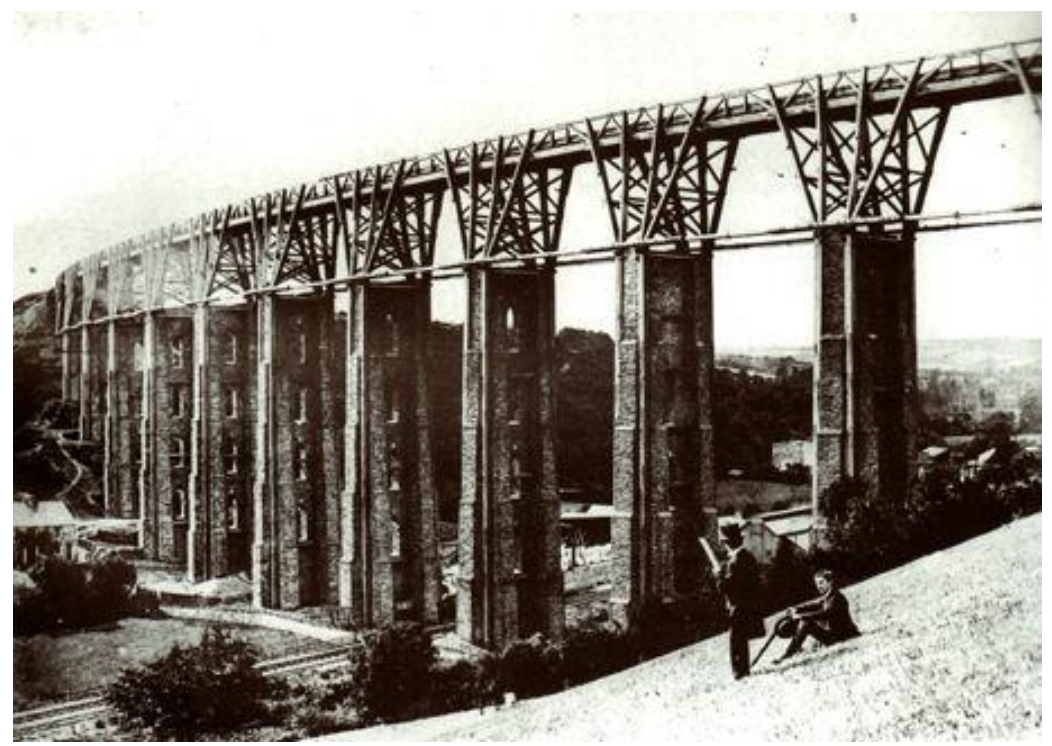

Fig. 4: Railway bridge at Moorswater, UK. The bottom part of the piers is made of masonry, whereas the upper part and the superstructure is made of wood.

From the second half of the nineteenth century onwards, with the advent of steel and reinforced concrete, wood began to be removed from the knowledge of the builders and the designers. However, since a few decades ago, there has been a "renaissance" of wood as a building material for large span structures. The reasons for this renaissance are probably to be sought in the development (and sometimes in the rediscovery) of:

- New wood-based materials such as Glulam, LVL (Laminated Veneer Lumber), CLT (Cross Laminate Timber), etc.

- New types of connectors and connections, for example self-tapping screws, connections made by means of slottedin plates and dowels, etc.

- New methods of wood protection, both chemical and structural-constructive

Timber structures with very large spans have been constructed over the past 30-40 years. Two representative examples are shortly described below:

- The Superior Dome, the world's largest wooden dome, opened on September 14, 1991 [3]. It is a stadium on the campus of Northern Michigan University in Marquette, Michigan, USA. It has a diameter of $163 \mathrm{~m}$ and a height (rise) of $49 \mathrm{~m} \mathrm{[3].} \mathrm{The} \mathrm{structure} \mathrm{is} \mathrm{a} \mathrm{geodesic} \mathrm{dome} \mathrm{with} \mathrm{glulam} \mathrm{ribs} \mathrm{made} \mathrm{of} \mathrm{douglas} \mathrm{fir.} \mathrm{It} \mathrm{is} \mathrm{designed} \mathrm{for} \mathrm{a}$ ground snow load of $3.4 \mathrm{kN} / \mathrm{m}^{2}$. See Figure 5 .
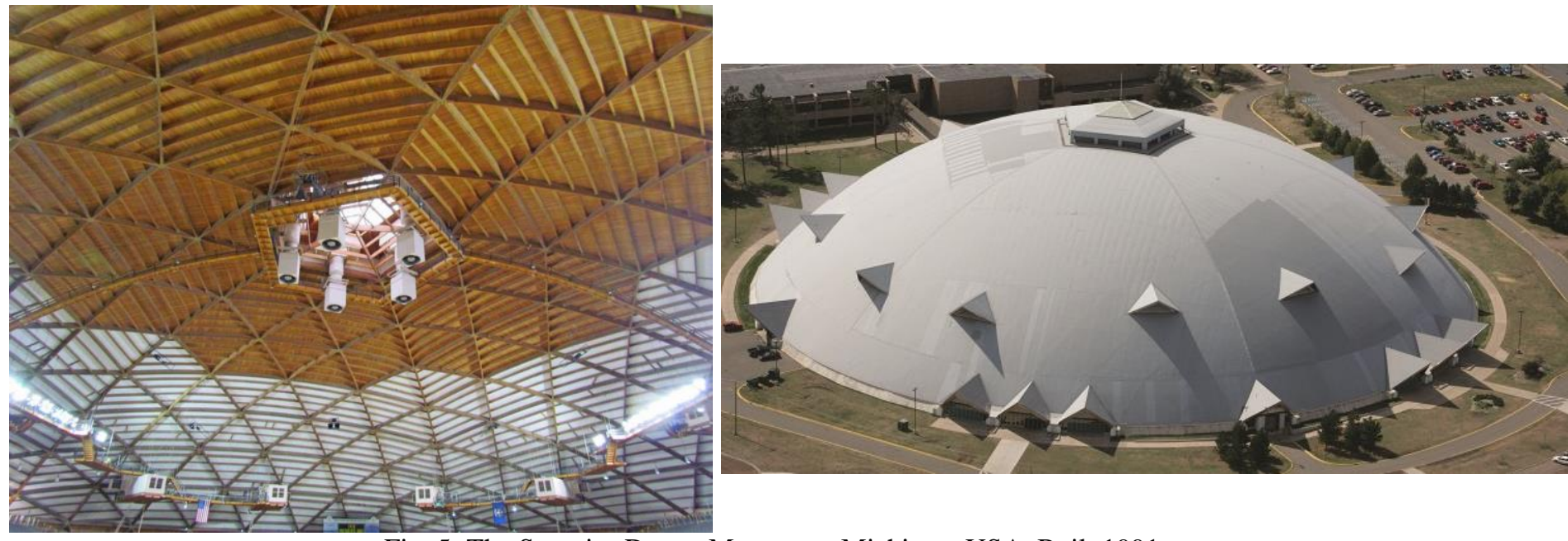

Fig. 5: The Superior Dome, Marquette, Michigan, USA. Built 1991. 
- The Viking ship in Hamar, Norway, built for the Olympic games in Lillehammer in 1994. To shape the arena, the architects were inspired by the "Oselver", a type of ship that has been built in Norway for a thousand years. The structure - which was designed for a ground snow load of $3.5 \mathrm{kN} / \mathrm{m}^{2}$ - consists of a number of parallel three-hinged trussed arches with the largest span of $96.4 \mathrm{~m}$. In order to give the shape of the boat to the roof, a dorsal arch has been added. This arch has mainly an aesthetical purpose and is supported by the other arches [4]. See Figure 6.
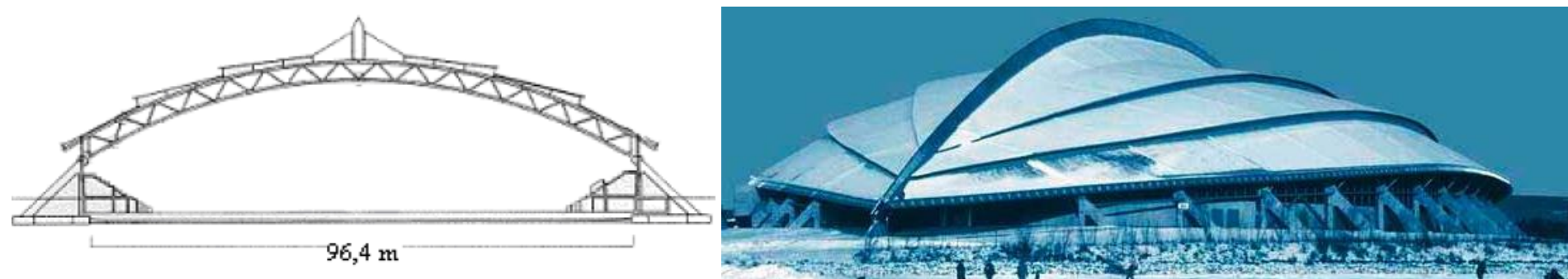

Fig. 6: The Viking ship in Hamar, Norway. Built 1994.

\section{Why Use Timber in Large Span Structures}

Depending upon the type of load to be resisted, i.e. compression, tension, bending, etc., different materials perform more or less efficiently. Considering firstly a simple tension member of cross-sectional area $A$ and a length $L$, one might investigate which material produces the lightest member when a tensile force is to be carried safely. In order to do that, one needs to maximise the ratio of load to weight, and take the conditions for that as a criterion for the efficiency of different materials when acting in tension. Simple calculations will show that maximum structural efficiency is obtained by the material having the maximum $f l \rho$ value - that is, the material with the highest tensile strength $(f)$ to density $(\rho)$ ratio. Similar considerations would apply when a stocky member - i.e. a member not prone to premature buckling failure - of the same material is subjected to compression. However, if a slender member with length $L$ is now to support a compression force $F$, buckling might become an issue. Ideally, a slender strut will support an axial load $\mathrm{P}_{\mathrm{cr}}=\pi^{2} E \cdot I / L^{2}$. Such a critical load, is evidently directly proportional to the bending stiffness of the cross section $(E \cdot I)$ rather than to its the axial capacity. Calculations show that choosing a material which maximises the ratio of $E^{1 / 2} / \rho$ will contribute to maximising the structural efficiency for compression members which are prone to buckling.

Similar computations can be performed in order to achieve the material efficiency criterion for the bending strength of beams. For a cantilever of length $L$ supporting a point load $F$ at the outer end, one will find that maximising the ratio of $f$ $2 / 3 / \rho$ will contribute to maximising the structural efficiency for bending strength. Lastly, studying the material efficiency related to bending stiffness, where the cantilever is as before, it can be found that when deflection is the issue, the material having the highest ratio of $E^{1 / 2} / \rho$ will be the most weight efficient [5].

Table 1: A comparison of some structural materials' abilities to resist tension, buckling and bending efficiently. The higher the number of the given ratio, the more efficient the material.

\begin{tabular}{|l|c|c|c|c|c|c|}
\hline Material & $\begin{array}{c}\text { Strength } f \\
{[\mathrm{MPa}]}\end{array}$ & $\begin{array}{c}\text { Density } \\
\rho \\
{\left[\mathrm{kg} / \mathrm{m}^{3}\right]}\end{array}$ & $\begin{array}{c}\text { Young's } \\
\text { modul } E \\
{[\mathrm{GPa}]}\end{array}$ & $\begin{array}{c}\text { Tension/compression } \\
\text { efficiency ratio } \\
f / \rho\end{array}$ & $\begin{array}{c}\text { Bending } \\
\text { efficiency ratio } \\
f^{2 / 3} / \rho\end{array}$ & $\begin{array}{c}\text { Deflection and buckling } \\
\text { efficiency ratio } \\
E^{1 / 2} / \rho\end{array}$ \\
\hline Softwood & $20-30$ & $350-450$ & $11-13$ & $44-85$ & $16-28$ & $7-10$ \\
\hline Carbon steel & $235-355$ & 7800 & 210 & $30-45$ & $5-7$ & 2 \\
\hline Concrete & $30-50$ & 2500 & 30 & $1-2^{(2)}$ & - & 2 \\
\hline CRFP (carbon fibres) & $500-1400$ & 1600 & $70-300$ & $300-900^{(3)}$ & $39-78$ & $5-11$ \\
\hline
\end{tabular}

(1) In case of compression, the values are usable only for members restrained against buckling

(2) Applies only for members in compression

(3) Applies only for member in tension 
Table 1 gives only a rough picture of the ability that different materials have to resist applied loads (in the computations it is disregarded that e.g. steel cross sections are commonly shaped in such a way that both the strength and the stiffness are optimized; consideration of that would have given higher efficiency ratios in bending and in deflection/buckling for the steel members). Though, the values exposed in the table give an indication that wood and especially CFRP, have the highest efficiency ratios, meaning that-from a pure structural standpoint - they should be the most adequate material to carry applied loads. However, CRFP likewise other reinforced polymer materials are still very expensive material and - most importantly from the environmental standpoint - they also need large amounts of energy to be produced. For this reason, their future use is likely to be rather limited, at least in civil engineering applications. Wood, on the other hand, due to both its outstanding mechanical properties, its inexpensiveness and its environmentally friendly nature, is expected to experience a strong revitalisation in the field of structural engineering, especially in large-span applications.

\section{Structural Efficiency and Structural Form}

The single most important parameter, for the design of efficient, load-bearing structures is without doubt the relationship between structural form and the configuration of the loads.

Generally speaking, a precondition for achieving efficiency in a structural system is that the loads are transported to the foundations as directly as possible. In an "ideal world" this ensures the shortest and most effective force paths, and thus contributes to keeping the weight down. However, in any civil engineering work, the design of spaces will mostly be in conflict with this ideal; the loads must necessarily be spread around in order to establish rooms, and are thus commonly deprived of the most direct path.

On the whole, structures are more efficient when loads cause axial forces in the system rather than bending. The main reason for this is that the internal stress distribution in axially loaded structures or structural members is more or less constant, and this uniform stress level provides for all of the material to be stressed to the limit. The same is obviously not the case for structures in bending, in which case the stress distribution reaches its maximum in the top and bottom fibres while being zero at the neutral axis, i.e. where the bending stress changes from compression to tension. Moreover, structures predominantly subjected to axial forces are also more efficient at resisting deformations. Deformations resulting from bending forces are commonly larger by far than those resulting from purely axial forces.

However, axially loaded members become thicker and heavier if they have to cope with buckling. Therefore, there is a difference between tension members and slender compression members regarding structural efficiency. Thus, structures are more efficient when resisting loads by tension forces rather than by compression forces. On the other hand, since compression members are nearly always present in structures, one should strive to design these with a low slenderness ratio, thus reducing the risk of buckling. This can be achieved, either trying to make compression members as short as possible or - whenever possible - brace these at regular intervals.

Timber structures that work predominantly in tension are not very common. Yet, there are some examples, e.g. so called cable-shaped structures, see section 4.3. Also, the structural members of numerous commonly adopted timber structures typically work in tension, e.g. tension ties or some of the web members in truss structures. It should be pointed out, however, that although members in tension are in general more efficient than member in compression, the opposite may be true when it comes to the design of adequate connections at the ends of the timber members.

From a structural point of view, the truss is more efficient than the beam due the reasons exposed above and also due to the larger "internal lever arm" of the former (see Figure 6). The suspension system, and the arch - if this is shaped according to the funicular of loads - are both very efficient structural systems, owing to the reason mentioned above. When the arch has the inverted (i.e. upside down) shape of the suspension system and if both are subjected to the same set of external load, only axials forces will develop in both structures. The magnitude of these forces is the same in both cases. However, there is a fundamental discrepancy between the axial force generated in the suspension system and that generated in the arch, being tension in the former and compression in the latter. Therefore, the possibility of premature buckling failure - i.e. a failure which occurs before the ultimate strength of the material has been reached - makes arches less efficient than suspension systems, see Figure 7. 


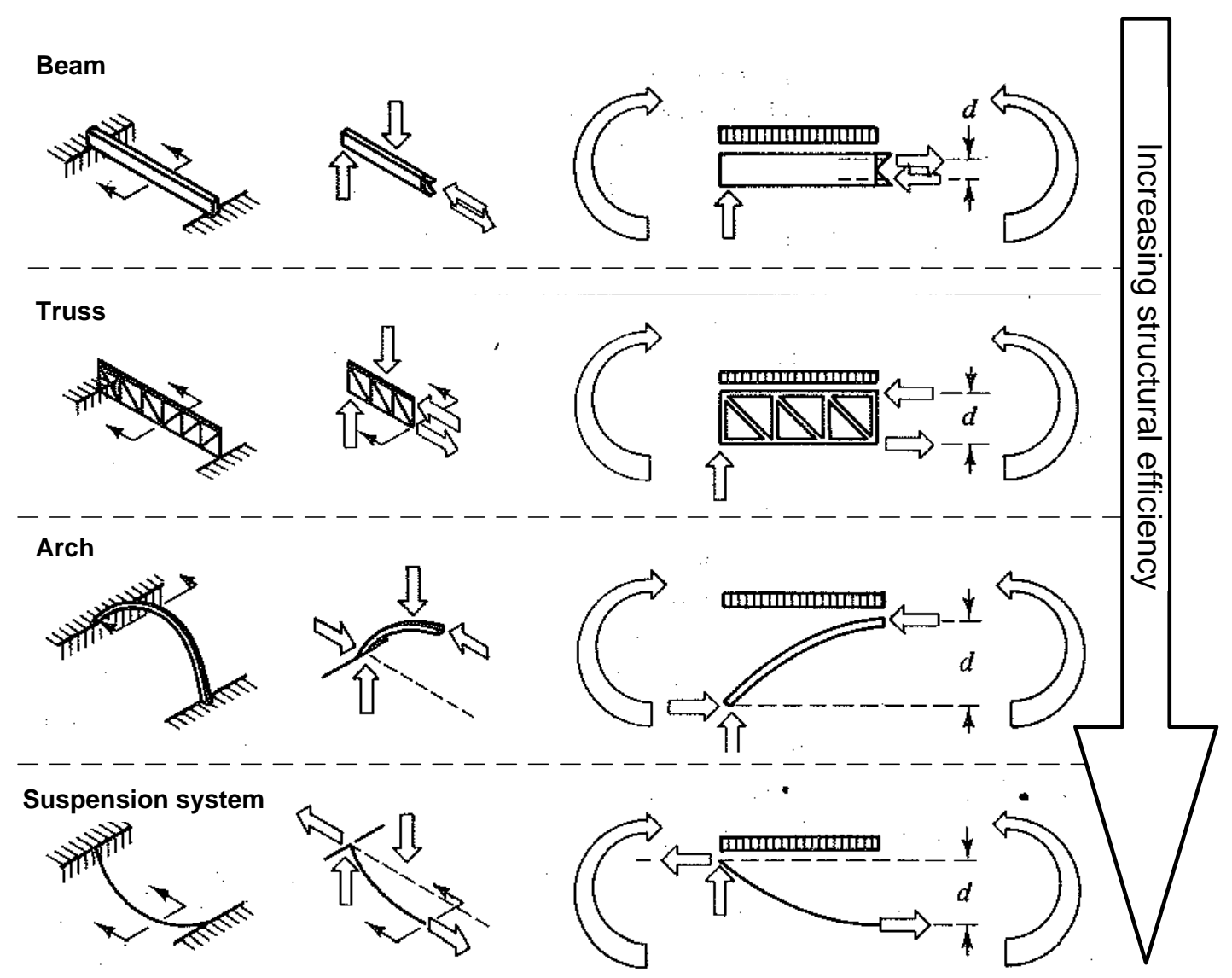

Fig. 7: Principle of load-bearing behaviour of different (planar) load bearing systems.

\section{Structural Types}

In this section some of the most common types of structural systems suitable for long-span timber structures will be dealt with, primarily in the forms of roofs and enclosures to house human activities. Particular emphasis will be given to planar timber structures. However, a few types of spatial (or space) structures also will be touched upon.

\subsection{Trusses}

A truss is a structure comprising one or more triangular units constructed with straight (or nearly straight) members the ends of which are connected at joints referred to as nodes. These triangular units are geometrically stable shapes. Timber trusses generally give an economic solution for spans over 25-30 m.

For large spans, trusses are typically spaced at 5 to $12 \mathrm{~m}$ centres, normally carrying purlins at 1.2 to $2.4 \mathrm{~m}$ spacings and supporting corrugated sheeting. Alternatively purlins are left out and instead heavier corrugated sheeting is applied directly on the trusses. Economy is usually achieved if the truss spacing increases with truss span.

In case the required architectural profile is at conflict with the "optimum" structural profile, high stresses may be introduced into the web system and the connections. Economy must then be achieved by adopting the most suitable structural arrangement of internal members with which it is possible to create an economical balance between materials and workmanship. In order to achieve this, the following aspects should be considered:

- The number of joints should be kept as low as possible because the workmanship for each joint is expensive, and also the joint slip at each node generally adds to the overall deflection of the truss.

- The slenderness of the compression chords and the internal struts must not be excessive.

- Local bending of the chords must not be too large.

- The angle between internal diagonals and the chords should be with a given range, typically $45^{\circ} \pm 10^{\circ}$. 
Transportation is frequently a limiting factor for deep or long-span trusses. Trusses deeper than $3 \mathrm{~m}$, or longer than 20 to $25 \mathrm{~m}$, require special attention. The transport problem can usually be overcome by a partial or complete disassembly of the truss.

Large trusses may have the main members spliced at one or more locations in the span, and in some cases the entire assembly can be carried out on site, although it is always preferable to carry out an initial assembly in the glulam factory to ensure correct fit and then disassembly for transport. A large range of alternatives is available for the general shapes of the trusses. Below, some of most common truss types are described.

Parallel-chord truss

Parallel-chord trusses are frequently specified as an alternative to glulam beams for long spans (typically over $25 \mathrm{~m}$ to $30 \mathrm{~m}$ ), where beams may be uneconomical. The loads in the web members are frequently very large, which causes some difficulty in providing adequate joints. The choice of web configuration is usually between the Howe, the Pratt and the Warren type, see Figure 8.

a)

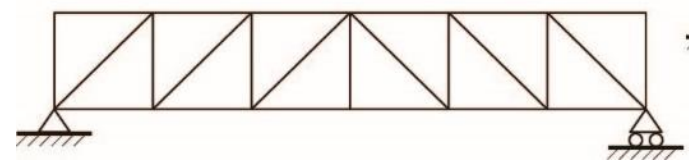

Fig. 8: Examples of parallel-chord trusses. b)

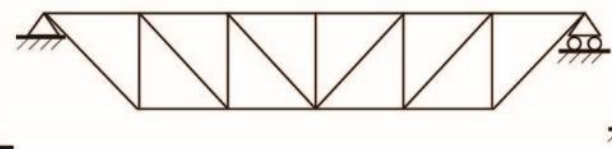

c)

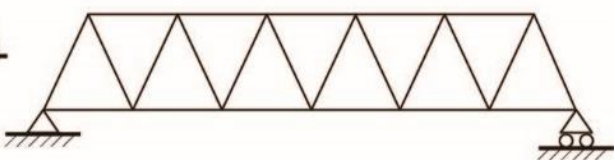

(a) Howe (diagonal in compression), (b) Pratt (diagonal in tension), (c) Warren (diagonals in alternating compression and tension).

The advantage of choosing a configuration with diagonals in compression rather than in tension is that the joints between diagonals and chords are relatively simple to construct, due to the fact that they can transmit loads by bearing stress. The disadvantage is, on the other hand, that the relatively long diagonals will be subjected to compression, thus prone for buckling. The Pratt-type configuration has the advantage that it can also be supported at its upper chord, which means that the centre of gravity of the truss is below the line between the two supports. This allows for an easier erection, due to the fact that, in case of initial out-of-plumb, the self-weight of the truss acts as a stabilising force against overturning. Parallel-chord trusses are often designed with a precamber that corresponds approximately to the deflection due to self-weight plus one half of the main variable load (e.g. snow load).

\section{Pitched trusses}

For uniformly distributed loads, the shape of pitched trusses fits the bending moment diagram reasonably well and is compatible with traditional roofing materials, such as purlins and/or corrugated sheeting. A portion of the applied load is transferred directly through the top chord members to the points of support, while the web members transfer loads of relatively small to medium magnitude and the joints can usually be designed to take these loads with little difficulty. In Figure 9 some different types of double pitched trusses are shown.

Double pitched trusses may have raised bottom chords to give extra central clearance, see Figure 9 (c) and (d). This can be particularly useful in storage buildings with central access.

\section{Bowstring and lenticular trusses}

For large-span uses, both bowstring and lenticular trusses, see Figure 10, can be very economical.

With uniform loading and no large concentrated loads the chords of the truss support almost all of the applied loading. This means that web members are loaded very little and thus the connections between diagonal and chords will be very simple and inexpensive. With these static systems, glulam trusses with spans in excess of $60 \mathrm{~m}$ to $70 \mathrm{~m}$ are easily achieved.

A parabolic profile is - from the point of view of statics - the most efficient choice to support uniform loading. However, practical manufacturing considerations usually make it more convenient or necessary to adopt a circular contour for chord members. The top chord member of bowstring trusses and each chord in lenticular trusses usually consists of two or more rigidly jointed curved glulam elements. The bottom chord of bowstring trusses usually consists of a number of steel rods. 
a)
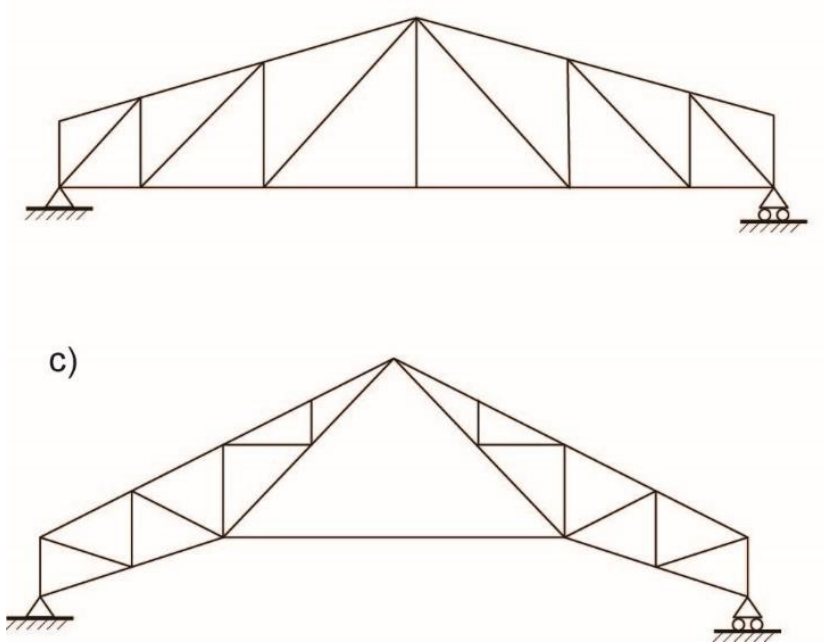

b)
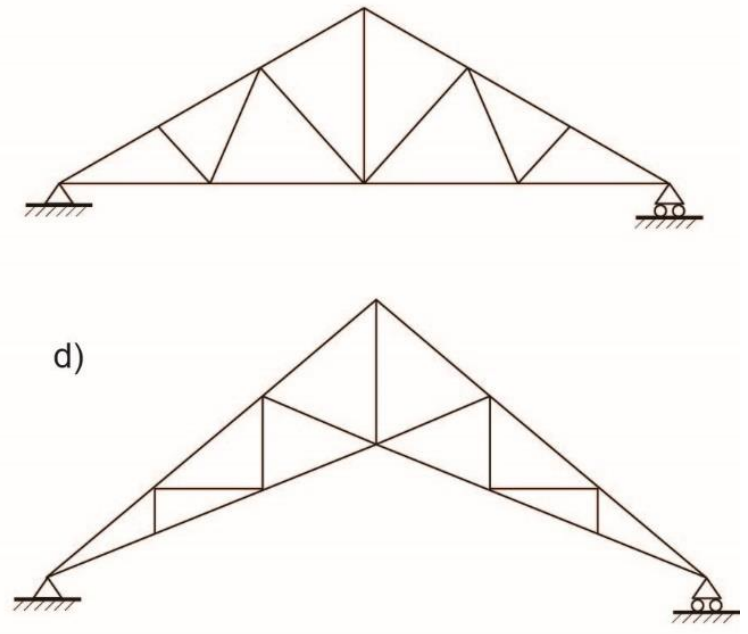

Fig. 9: Examples of double pitched trusses. (a) Trapezoidal (Howe-type), (b) Triangular with horizontal bottom chord, (c) Triangular with raised bottom chord, (d) Scissor type.
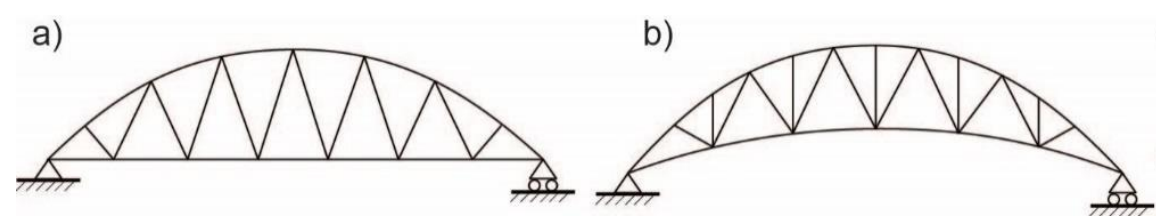

c)

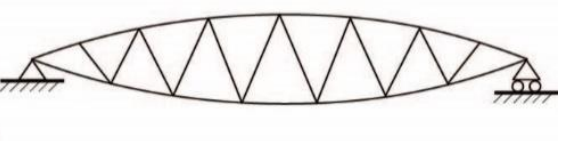

Fig. 10: Examples of bowstring and lenticular trusses. (a) Bowstring with horizontal bottom chord, (b) Bowstring with raised bottom chord, (c) Lenticular truss.

Generally, architectural considerations determine the shape and possibly the slope of the roof. Also the need of services such as ventilation ducts, which pass through the truss, can influence the choice of the profile. However, for economic reasons "rules of thumb" concerning depth-to-span ratios, maximum span etc. should be followed. Figure 11 gives indications for preliminary design of three typical truss types.

(a

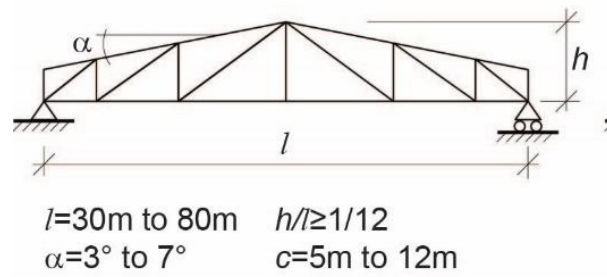

(b

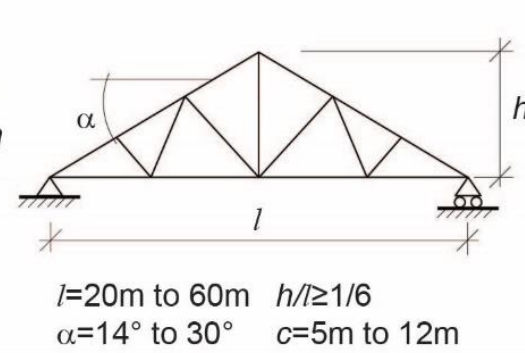

(c

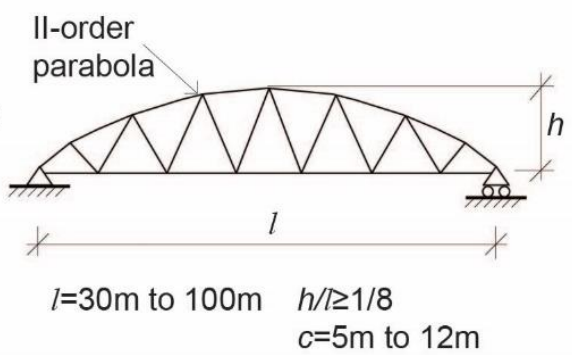

Fig. 11: Preliminary design of three different truss types. "c" is the centre-to-centre distance between adjacent trusses.

The following issues should be kept in mind during the preliminary design process:

- The secondary load bearing system, e.g. purlins in the direction perpendicular to the trusses, should be compatible with the truss triangulation system so that the transmission of loads occurs at (or as close as possible to) the nodes.

- For the sake of economy, design with diagonals in compression (e.g. the Howe type truss) is often preferred for timber trusses designed for moderate loads in the members. If the diagonals are in tension, in fact, the nodes will have to transmit tensile forces. In timber structures, nodes subjected to tension are normally rather complicated and time-consuming to construct and they almost necessarily require steel assemblies in order to transfer forces 
from one member to another. On the other hand, truss design with diagonals in compression allows the diagonal members to transfer their forces to the vertical and horizontal members by bearing directly against them; and timber members tend to be thick enough to make it less likely for buckling to be a problem, than e.g. in steel members. When the loads in a truss member are very large, however, load transmission by bearing pressure may not be sufficient. In such a case, thus, the use of steel assemblies would be indispensable and from the point of view of economy it does not matter whether the diagonals are arranged so that they are in tension or in compression.

- In order to ensure a good efficiency of the truss, the angle between the diagonals and the chords should be close to $45^{\circ} \pm 10^{\circ}$.

General rules for sizing of the members

The breadth to depth ratio of the members should be chosen taking into consideration the type of connection, which will be used for the nodes of the truss. As an example, consider a connection made of slotted-in plates and dowels, which is very often used in nodes of large-span trusses, see Figure 12. In order to increase the load bearing capacity of the nodes, it is often necessary to use a large number of slotted-in plates; this requires the choice of relatively wide cross sections so that the plates can be accommodated.

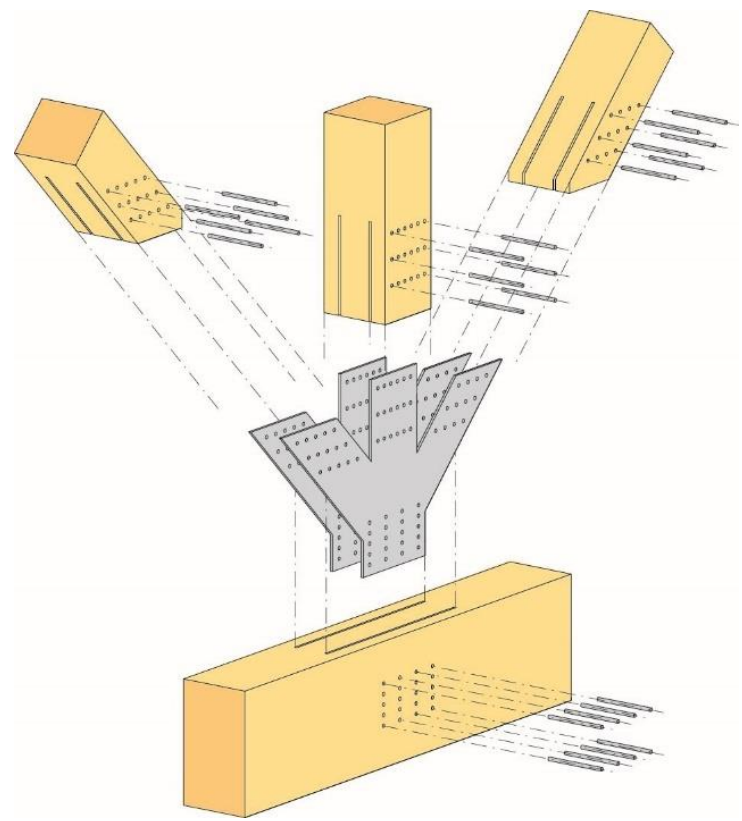

Fig. 12: Typical truss node with slotted-in plates and dowels.

The bending stiffnesses of the single members in the plane of the truss should be kept reasonably small in comparison to the bending stiffness of the assembled truss. In fact, in such a case, the bending moments at the nodes will be small and normally they can be neglected; thus, the truss can be analysed with satisfactory approximation by assuming all its members to be hinged at their ends. The presumption that the bending stiffness of the members is small in comparison to the bending stiffness of the assembled truss, is normally fulfilled if the chord depths do not exceed 1/7 of the truss depth, see Figure 13.

For this reason, nearly square-shaped cross sections are often used for compression members and square or rectangular cross sections (with the largest side in the direction perpendicular to the plane of the truss) for tension members. The choice of relatively shallow cross sections (in the plane of the truss) has also the advantage of facilitating the design of nodes without eccentricities.

Buckling of compression members

Compression members and members subjected to combined compression and bending (normally the members in the upper chord of the truss) shall be designed similarly to beam-columns, taking into account the risk of buckling both in the plane of the truss and out-of-plane. 
For chord members in general, and for out-of-plane buckling of web members, the buckling length $l_{\text {cr }}$ may be taken as equal to the system length $l$. The in-plane system length is the distance between the joints. The out-of-plane system length is the distance between the lateral supports, see Figure 13.

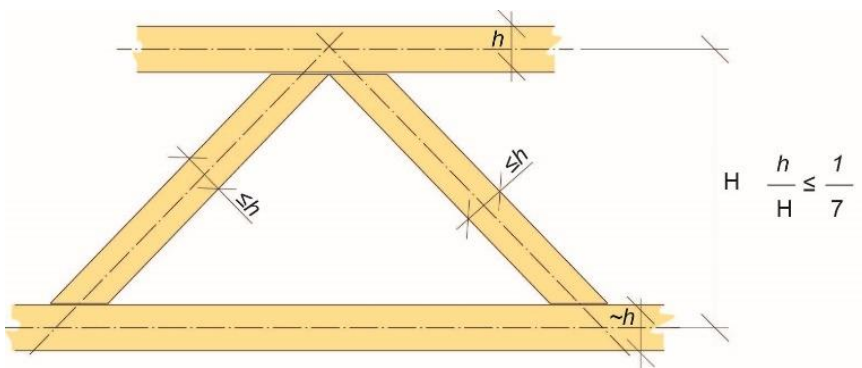

Fig. 13: Ratio between member depths and truss depth to reduce the influence of bending moments.

a)

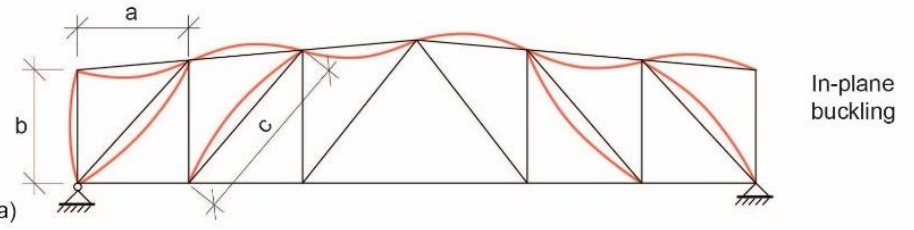

b)

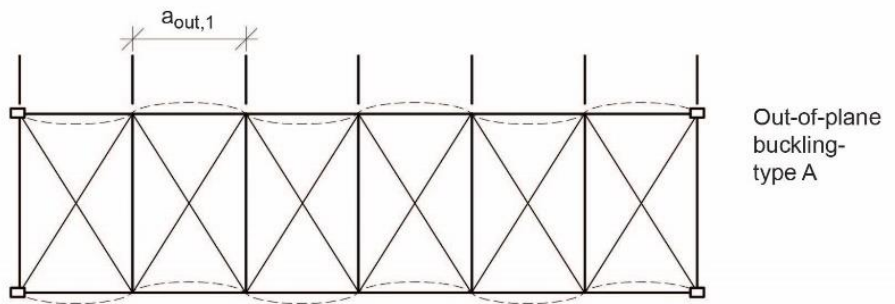

c)

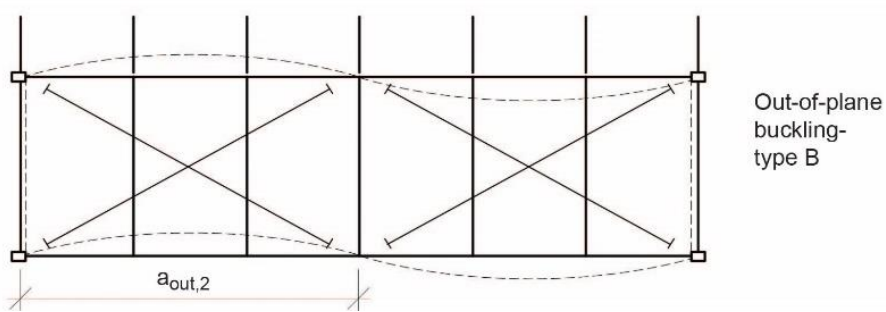

Fig. 14: Examples of assessing the theoretical buckling lengths in trusses.

In order to reduce the out-of-plane buckling length (if necessary) it is possible to brace the members, e.g. as shown in Figure 13 (b) and (c). For a roof with a bracing system type A shown in Figure 14, the supporting points are defined by those purlins, which are attached to the immovable joints of transverse roof bracing. For a roof with bracing system type B, the upper chord may buckle out-of-plane along a few panels of the web of the truss. It should be noticed that the bottom chord may also be subjected to buckling, in the case when the wind uplift is larger than the permanent loads.

Details

Quality, durability and above all manufacture costs of trusses depend to a large extent on the choice of the joints used to build the nodes. Trusses normally include large number of nodes. It is advisable therefore, to choose node solutions with the following properties:

- Member centre-lines shall meet at one and the same point in nodes.

- Has a concentrated lay-out with small extension.

- Be easy and fast to assemble.

- Appropriate fire resistance, if required.

- Limit the amount of steel parts. 
- Be of "standard type", i.e. it should be possible to use the same type of connection for as many nodes of the same truss as possible.

For trusses consisting of single chords and single web members, the connection types used at the nodes normally include steel plates and dowel-type connections (typically dowels or bolts). Figure 15 shows two types of typical node solutions, a) with external steel plate and bolts, and b) with slotted-in plates and dowels. Nodes that adopt solutions similar to that of Figure 11, sometimes with significantly larger number of slotted-in plates, are suitable for trusses with very large spans (up to $70 \mathrm{~m}$ to $80 \mathrm{~m}$ ) and/or heavy loads.

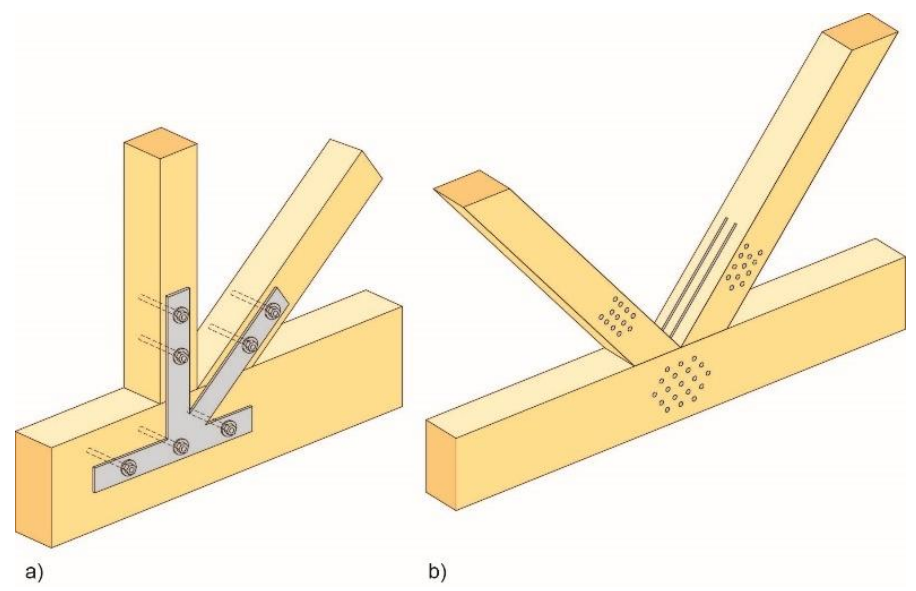

Fig. 15: (a) Truss node with external steel plates and bolts and (b) truss node with slotted-in plates and dowels.

In Norway and Sweden, several large glulam trusses, both for industrial, commercial, and sport buildings and also for bridges, have been constructed using connections with slotted-in plates and dowels. For such type of connections it is common praxis in these countries since the beginning of the 1990's to use slotted-in plates with thickness $t=8 \mathrm{~mm}$ and dowels with diameter $\mathrm{d}=12 \mathrm{~mm}$. Glulam type GL30c or GL30h is used for truss members and common mild steel for the steel parts (e.g. S355). In order to optimise the connection from the point of view of strength and at the same time ensure satisfactory structural ductility, the spacing between slotted-in plates, the spacing between connectors, the distance between dowel and loaded end and the distance between dowel and unloaded edge should be chosen according to Figure 16 . Special attention should be paid to possible block shear failures, which are particularly relevant in case of several slotted-in plates in combination with a large number of dowels.
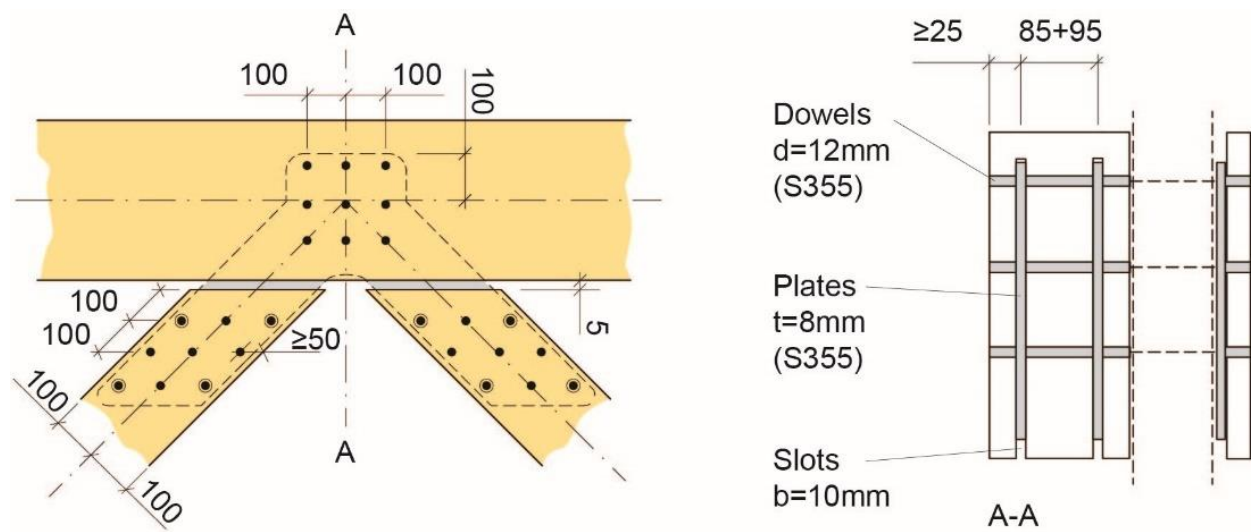

Fig. 16: (a) Typical truss node used in Norway and Sweden with spacing indications. Up to 8 to -9 slotted-in plates have been used for very heavy glulam trusses. 
Figure 17 shows one of the load bearing truss of the Hamar olympic amphitheatre during construction, before the olympic games in Norway in 1994. The structural type is a bowstring truss with horizontal bottom chord. The span of the truss is $71 \mathrm{~m}$, which means that - due to manufacturing and transportation reasons - the chords of the trusses needed to be spliced. The bottom chord splice was designed for a design tension force of $7000 \mathrm{kN}$, which was extremely challenging. The joint adopted was a dowel connection with several slotted-in plates similar - in its principle - to that shown in Figures 16.

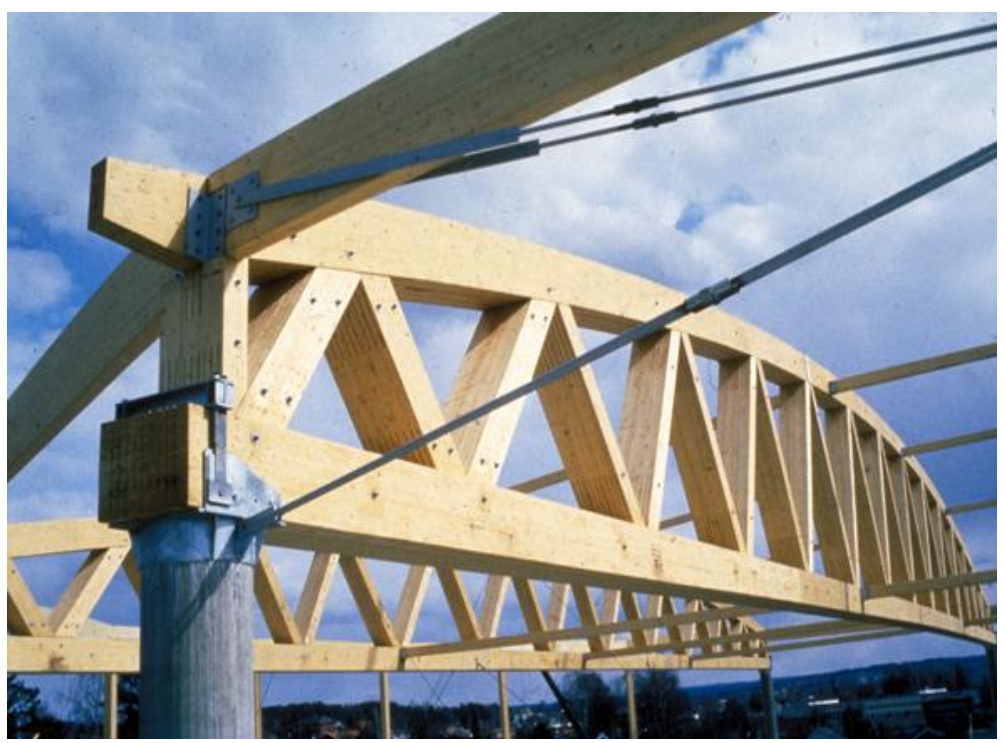

Fig. 17: Main truss of the Hamar olympic amphitheatre, Norway. The span is $71 \mathrm{~m}$. The truss nodes consists of slotted-in plates and dowels (Photo: Moelven Limtre A/S).

\subsection{Arches}

Arches are structures very suitable for execution in timber - a material which without a great increase in price can be produced in curved forms and with varying depth. As a rule, arches with solid sections of constant depth are made, but composite sections of I- or box-shape also occur, especially for large spans.

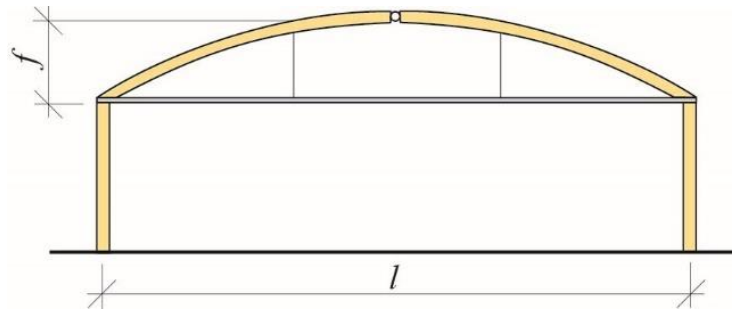

Fig. 18: Arch with tension tie, on columns.

The form of the arch should be chosen so that the bending moments are as small as possible. This means that the arch geometry should follow the thrust line of the dominating loading combination. The influence of moments cannot be avoided completely, however, since several load combinations must be taken into account, each with its own thrust line. As a compromise a parabola is often chosen, or a circle with a rise-to-span ratio $f / l$ of approximately 0.14 to 0.15 . For functional reasons, e.g. in order to increase the headroom near the supports, the arch can be placed on columns, see Figure 18 . The horizontal support reactions caused by the arch must in this case be taken by a tension tie between the springing points of the arch.

When the arch rests directly on the ground floor concrete slab or on an abutment, e.g. as in Figure 19, the horizontal forces can be taken up by the foundations if ground conditions permit, see Figure 19(b), or by tie rods under or within the floor, see Figure 19 (c). In order to limit the size of the horizontal reactions the rise of the arch should be equal to or greater than 0.14 to 0.15 of its span. For a parabola or a circle this corresponds to an angle of spring of approximately $30^{\circ}$. In practice, arches are normally designed with a rise-to-span ratio $0.14 \leq f / \leq 0.30$. 


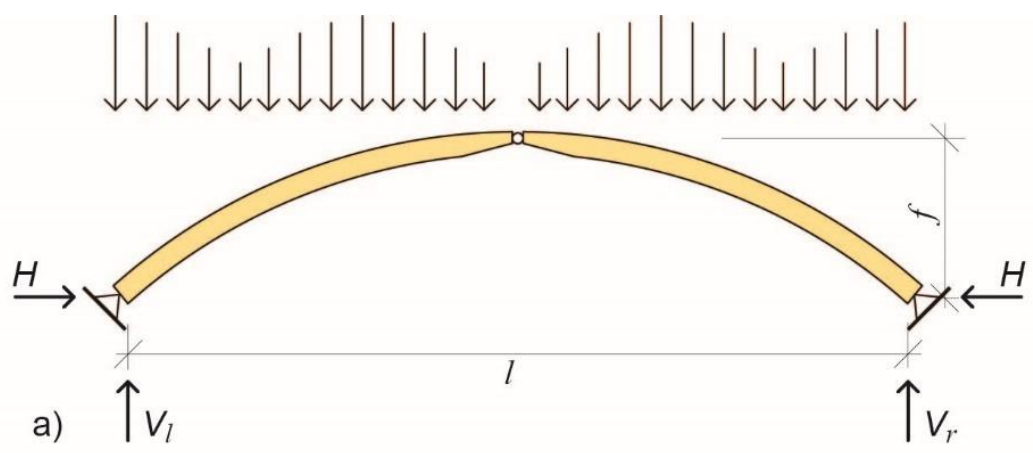

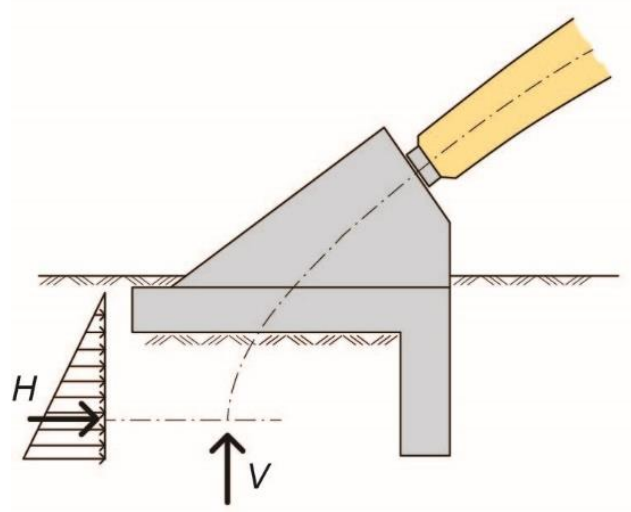

b)

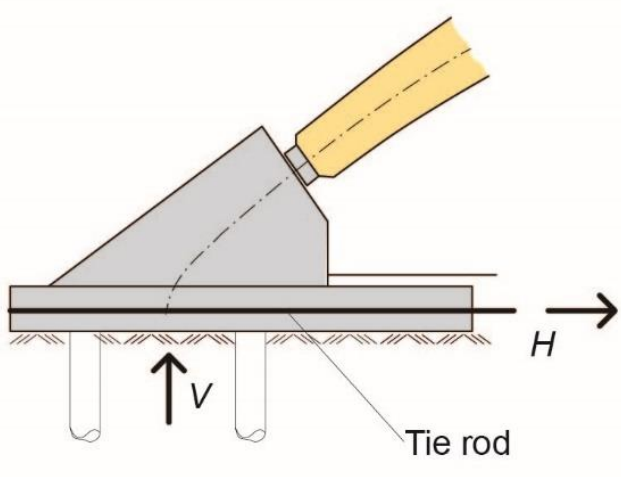

C)

Fig. 19: Arch springing from foundations; (b) the horizontal thrust is taken directly by the abutment and foundation; (c) the horizontal force is taken by a tie rod in the slab.

The choice between two- and three-hinged arches is made based on manufacturing and transportation considerations. Three-hinged arches are thus preferable for spans of up to 60-70 metres, while larger spans usually demand that the arch is manufactured and transported in three or more parts, which are joined rigidly on the site. In such a case, a system with hinges placed only at the abutments is chosen (two-hinged arch). Hinges and rigid joints should be placed as in Figure 20. The twohinged arch has the inconvenience of being statically indeterminate, which means that it is sensitive to e.g. support settlements or/and moisture changes. Hingeless arches are in practice never employed for load-bearing timber structures.

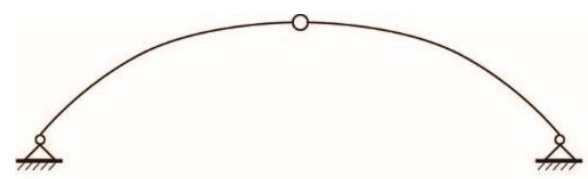

a)

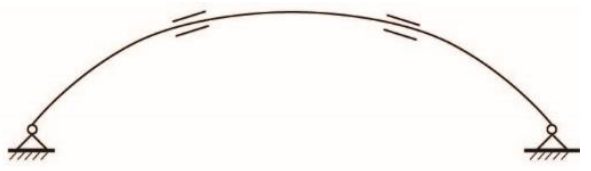

b)

Fig. 20: Suitable placing of joints in arch structures. a) three-hinged arch; b) two-hinged arch.

It should be noted that arches are in general not recommended in case of presence of large concentrated loads. In fact, isolated such loads will increase the distance between the thrust line and the geometrical axis of the arch, which in turn will increase the magnitude of bending moments in the structure. Large concentrated loads thus dramatically reduce the "archlike behaviour" of the structure. The effect of such loads is less negative in case of roofs with heavy permanent, uniformly distributed loads.

According to some building codes, such as Eurocode 1-3, drifted snow load arrangements, with triangular load distributions on each half of the arch should be considered during design, see Figure 21. Such load condition gives rise to relatively large bending moments in the arch, especially when the span is large. One method to reduce the effect of bending 
moments could be e.g. to increase the "internal lever arm" of the arch, for example by creating a trussed arch, such as that of Figure 6, or by choosing an arch structure, where each half consists of a lenticular truss, see Figure 21 (b).

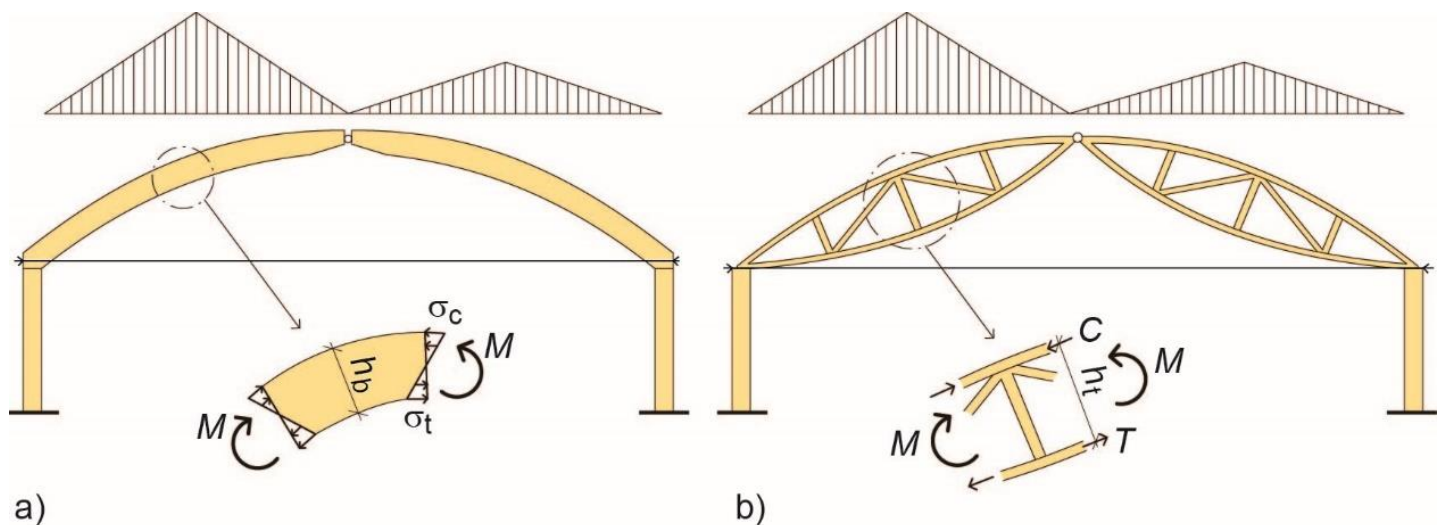

Fig. 21: Arch structures subjected to triangular load distribution. (a) Common arch structure; (b) Arch structure consisting of two lenticular trusses connected at the ridge. The effect of relatively large local bending moments $\mathrm{M}$ (case a) can significantly be reduced by choosing a structure with larger internal lever arm (case b).

The three-hinged arch is the most common type of glulam arches. Therefore, only indications concerning the design of such types of arches will be given in the next sections.

Conceptual design

Generally, architectural considerations determine the shape and possibly the rise of the arch. However, for economic reasons and also in order to limit the horizontal thrust, some "rules of thumb" concerning depth-to-span ratios, maximum span etc. should be followed. Figure 22 gives indications for preliminary design of three typical arch profiles.

Two-hinge arch

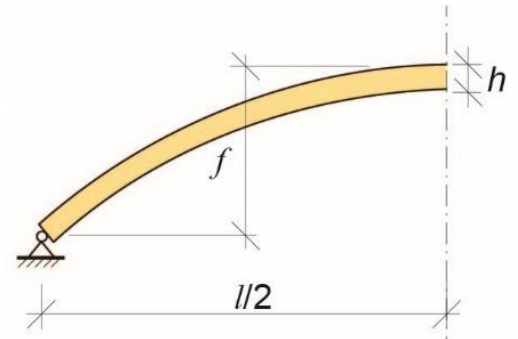

$l=30-100 \mathrm{~m} ; h=l / 50-l / 30 ; f \geq l / 10$

a)
Three-hinge arch

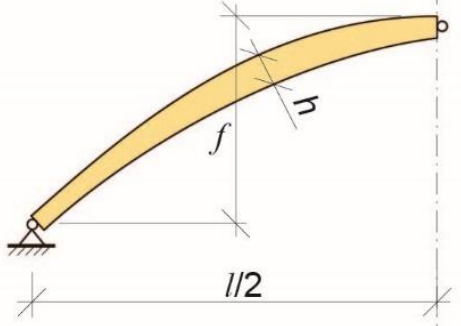

$l=30-100 \mathrm{~m} ; h=l / 50-l / 30 ; f \geq l / 7$

b)

\section{Trussed arch}

(two- or three-hinge)

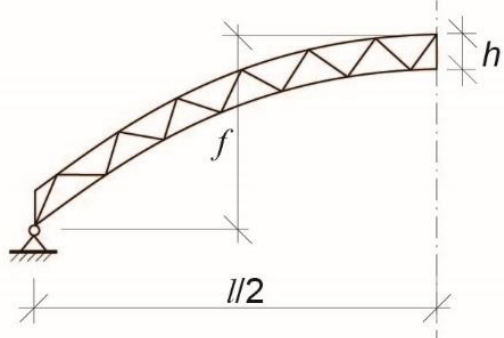

$l=50-120 \mathrm{~m} ; h=l / 40-l / 20 ; f \geq l / 8$

c)

Fig. 22: Preliminary design guidance for three different arch types.

\section{Design of three-hinged arches}

The three-hinged arch is stable against horizontal forces in its own plane and statically determinate, which means that the moment distribution is not affected by uneven settlement of the foundations or by unforeseen deformations in joints and connections. Further, the three-hinged arch has hinges at the springing points, which simplifies the construction of the foundations. In poor soil conditions, the horizontal reactions at the supports can be taken by tension members between the foundations (located within or under the slab).

Stability control

Arches are as a rule slender structures and the design must therefore - even to a larger extent than for frames - be carried out by taking the risk of buckling into account, i.e. both in-plane and out-of-plane buckling. 
An arch, which lies in one vertical plane, must be prevented from toppling over sideways, see Figure 23(a). This phenomenon is particularly relevant during erection. Two methods may be adopted to prevent this. One has fixed connections at the base, which is rather cumbersome to achieve and which also requires - especially in the case of large structures - a massive foundation to prevent overturning. Another, more commonly used method for achieving lateral stability during construction, is to erect two adjacent arches simultaneously. The arches are in this case provided with a temporary or permanent bracing, which prevents the structure from collapsing, see Figure 23(b).

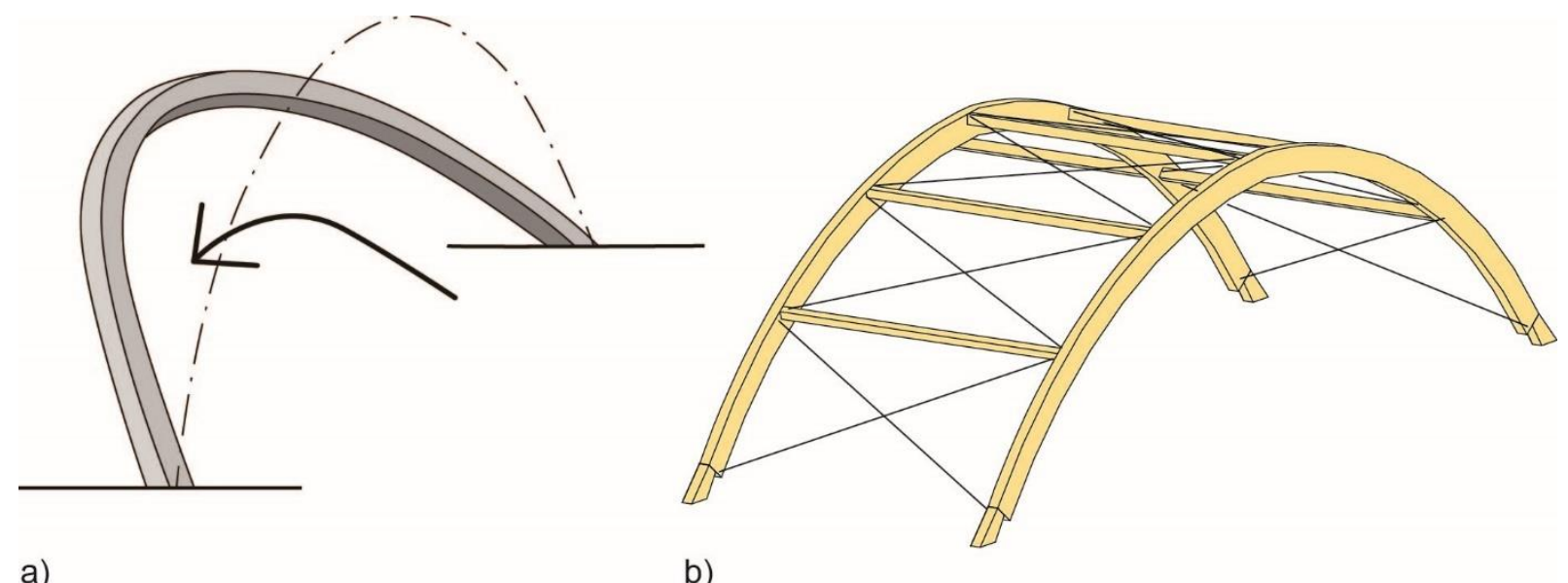

Fig. 23: Considerations concerning the lateral behaviour of arches during erection. (a) Possible toppling over of an arch sideways (overturning); (b) The lateral stability can be achieved by lateral bracing of arches with other elements, such as purlins from the roof structure in combination with cross-bracing.

The second major problem with respect to the behaviour of frames and arches in the lateral direction is that of lateral buckling (i.e. out-of-plane buckling). Since timber elements can be fairly slender, out-of-plane buckling of the type illustrated in Figure 24 may occur.

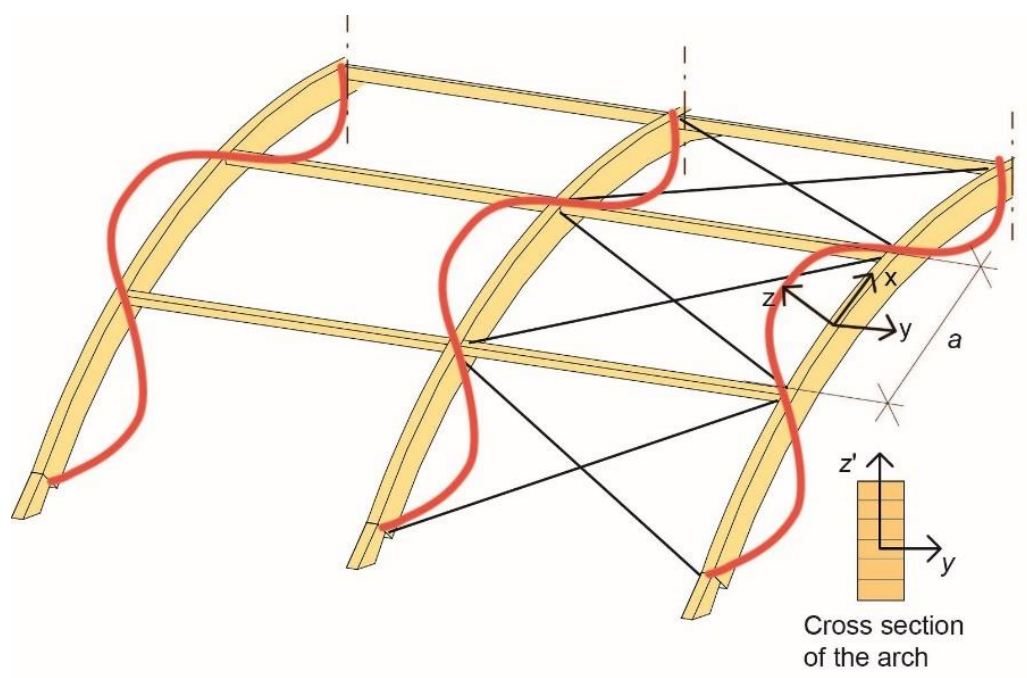

Fig. 24: Lateral buckling of braced arches; bracings with spacing a.

One method to increase the stability with respect to out-of-plane buckling is to increase the stiffness of the frame or the arch in the lateral direction by increased lateral dimension. Another method is to reduce the centre-to-centre distance between purlins or to use stiff sheeting at the top of the purlins. Obviously the purlins must be connected to the arches with proper joints suitable for the transmission of bracing forces. In normal arches, out-of-plane buckling is checked in the same 
way as any other beam-column between lateral restraints. These bracings make the effective length of each element easily identifiable.

Buckling in the plane of the arch is in general more complicated than for normal beam-column members. The common methods of analysis for arches are the following:

- Linear buckling analysis.

- Non-linear analysis.

If linear buckling analysis is adopted, arches can be verified in the same manner as beam-columns, i.e. members subjected to simultaneous action of bending and compression. The calculation of stresses due to external loading is based on linear elastic theory considering the equilibrium of the undeformed static system. Stresses caused by in-plane and lateral imperfections and induced deflections are taken into account by multiplying the compression and bending strength values by buckling reduction factors, $k_{c}$ and $k_{c r i t}$, respectively, as recommended in [9].

Two-hinged arches always buckle in asymmetrical configurations, regardless whether the load is symmetrical or nonsymmetrical. This means that the crown moves horizontally and becomes a point of contraflexure, see Figure 25 . In the case of three-hinged arches, however, for high rise-to-span ratios (i.e. $f />0.3$ ) the buckling mode may be symmetrical, even if the loading is asymmetrical.

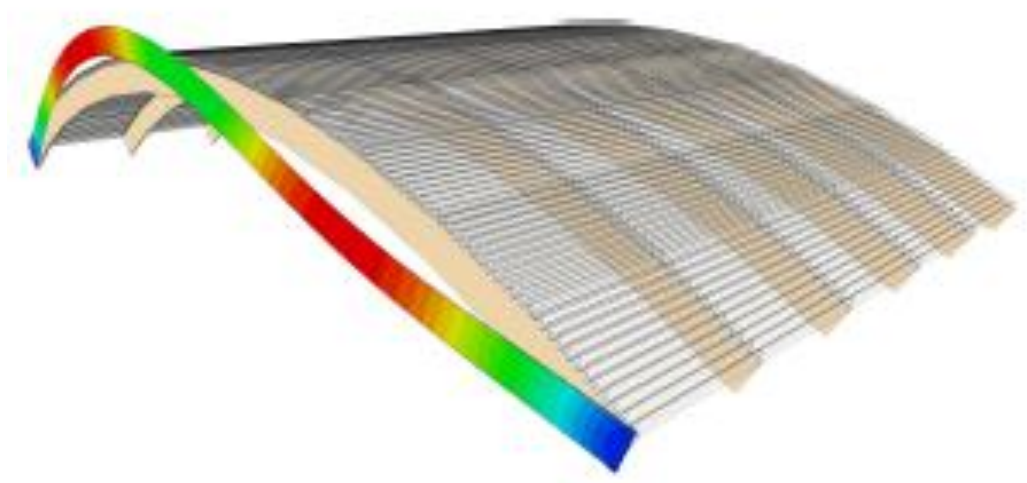

Fig. 25: In-plane buckling mode, typical for two and of three-hinged arches, after [8].

For the determination of the buckling load according to the simplified analysis, the buckling load is given by the wellknown Euler equation $\mathrm{N}_{\mathrm{cr}}=\pi^{2} \cdot \mathrm{E} \cdot \mathrm{I} /\left(l_{c r}\right)^{2}$, where $\mathrm{E} \cdot \mathrm{I}$ is the bending stiffness in the plane of the arch and $l_{c r}$ is critical length. Such a length can be determined either $a$ ) numerically, e.g. by means of a linear buckling analysis performed by a finite element computer programme or $b$ ) by empirical formulas. A safe assumption for two and three hinged arches is $l_{c r}=1.25 s$, where $s$ is the length of one half of the arch.

When non-linear analysis is adopted, the calculation of stresses is based on a geometric nonlinear theory considering the equilibrium of the deformed static system. In nonlinear analyses, design loads are gradually applied in increments. Before an incremental load is applied on the structure, displacements due to previously applied loads are calculated. Incremental loads are applied at locations worked out after adding displacements due to previously applied loads. Thus the effect of all displacements, including horizontal sway, due to previously applied loads, on member forces is considered in the nonlinear analysis. This type of analysis is commonly performed by means of adequate finite element based computer programmes. If initial imperfections are also input in the model, member forces given by second order analysis can be directly used for member design, without reduction of the design strength due to buckling (i.e._ $k_{c}=1,0$ ). Typical initial imperfections used as an input for the non-linear analysis are shown in Figure 24. 


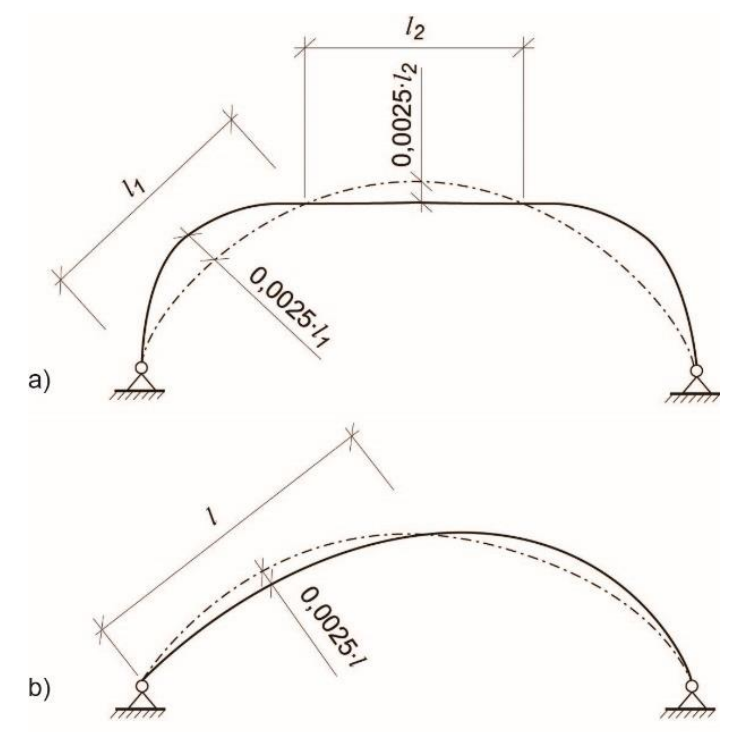

Fig. 26: Recommended assumptions for initial deviation in the geometry of arches according to [9]. (a) symmetric (assumed) initial imperfection shape, affine with the second buckling mode of a two-hinged arch;(b) asymmetric (or sway mode) imperfection shape affine with the first buckling mode.

\section{Details}

The connections at springing points of arches are designed as nearly moment-free hinges. Depending on the choice of the connection type, relatively small moments are likely to be transferred. However, they are usually of such limited magnitude, that they do not need to be taken into account when designing the arch, although they will be of importance, when designing the connection itself and its anchorage.

Besides allowing for rotations around the strong axis, the connection must also be able to transmit both vertical and horizontal forces. See Figure 27.

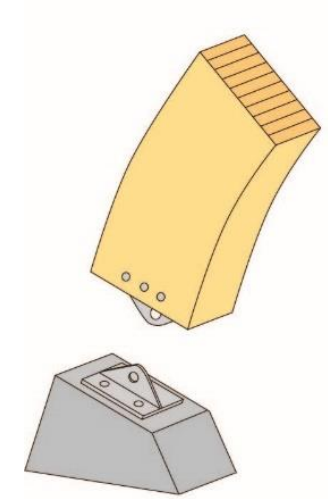

a)

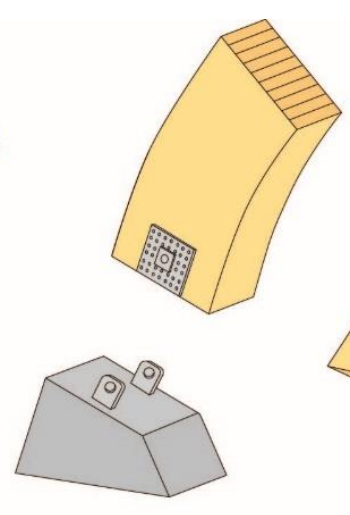

b)

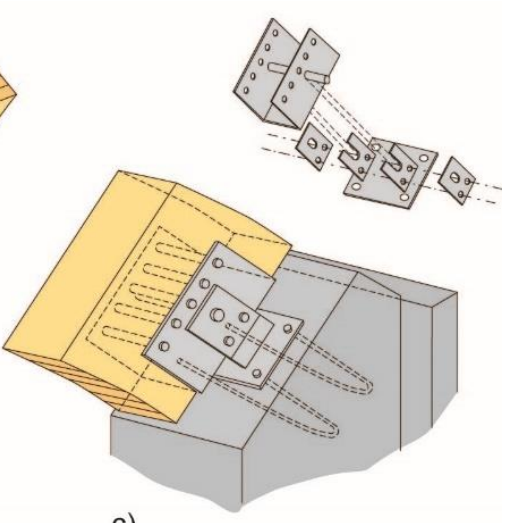

c)

Fig. 27: Possible arch base details of arches: (a) with end plate and hinge pin; (b) with nail plates and hinge pin; (c) with end U-shaped plate, hinge pin and side lugs.

Hinged ridge joints transfer horizontal and vertical forces. Moments are transferred only to a limited extent and are generally not taken into account in the design. The connection should not restrict changes of angle in the beams. If this movement cannot take place extra stresses will arise, which can lead to unforeseen damage to the structure. Some other possible solutions for hinged ridge joints are shown in Figure 28. 


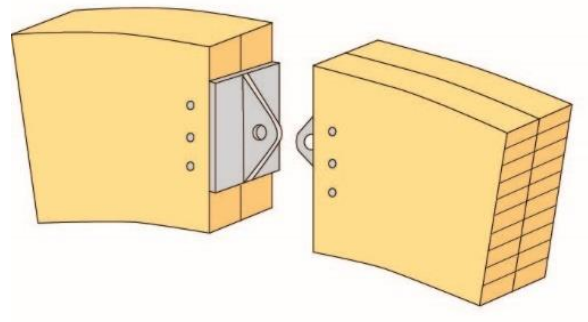

a)
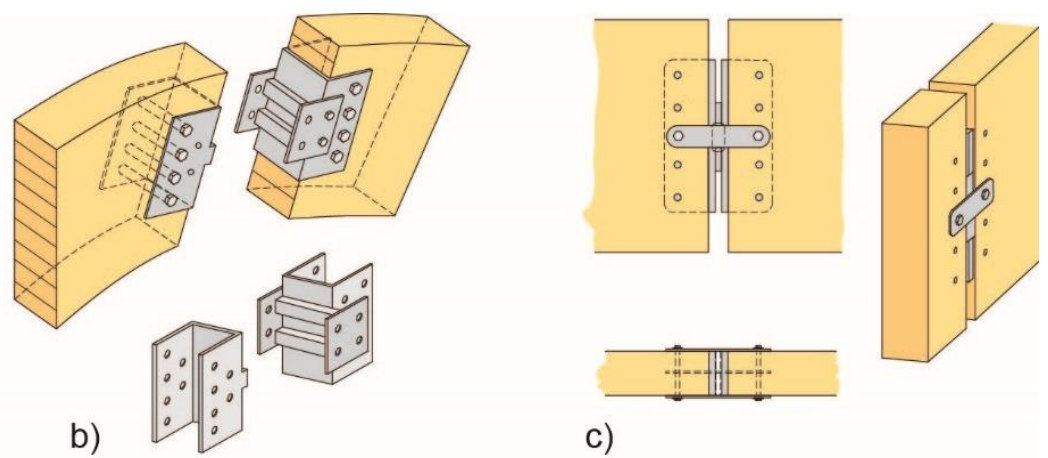

c)

Fig. 28: Hinged ridge joint. (a) with dowelled steel plate, end plate and hinge pin; (b) with end plate, rocker ribs and side lugs; (c) with dowelled end plate, rocker ribs and side lugs.

Figure 29 shows a three-hinged arch timber bridge in Branäs, Sweden. The bridge was built in 2008 and it is designed for contemporaneously pedestrian load and snow (the bridges is mainly used by skiers). The bridge's total length is $130 \mathrm{~m}$, the arch span being $50 \mathrm{~m}$. In the same figure, it is also exposed a detail of the springing of the arch, which is fairly a "perfect" hinge. In the same detail, two steel rods are also visible; these are part of the arch lateral bracing system.

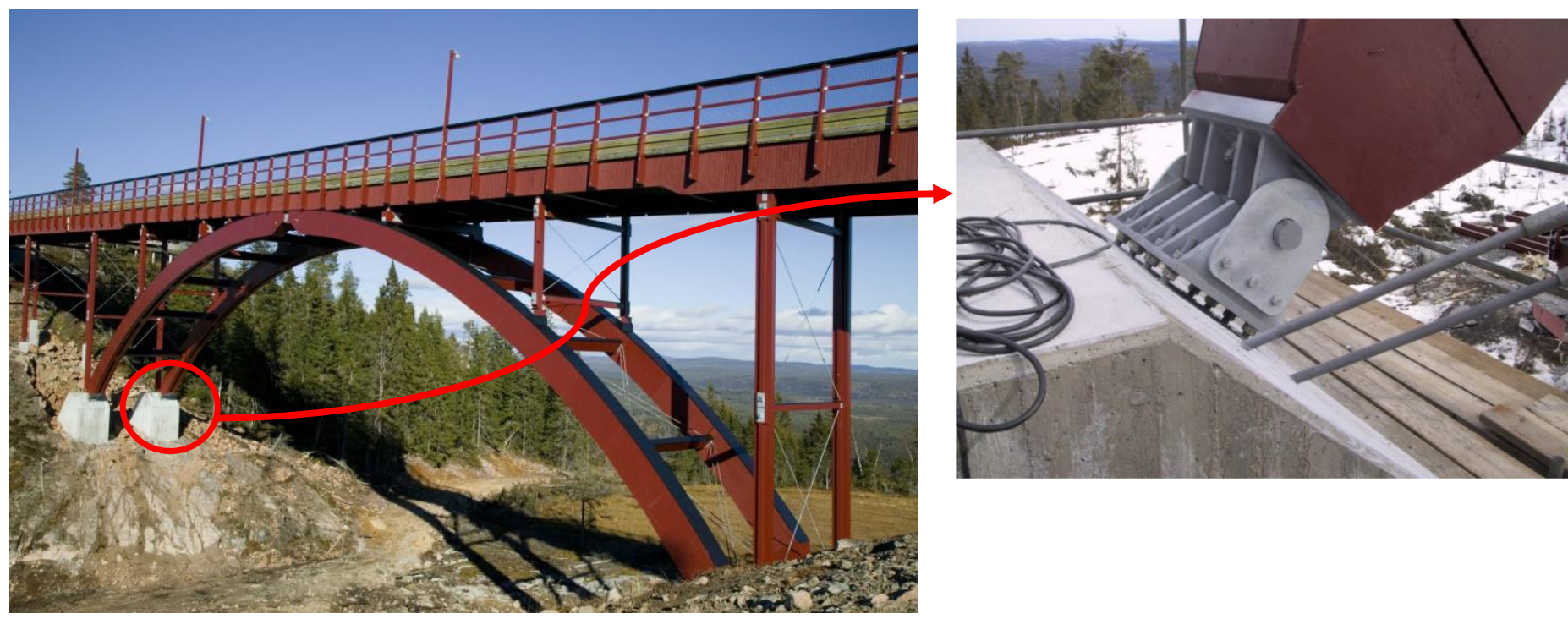

Fig. 29: Arch bridge of timber in Sweden. The total length of the bridge is $130 \mathrm{~m}$, the span of the arch being $50 \mathrm{~m}$. To the left a detail of the hinge at one of the springing points of the arch.

\subsection{Special structures}

In the following, some other less common timber structural systems, in this context regarded as to "special structures" will be briefly presented, namely:

- Cable shaped structures and

- Spatial (or space) structures

The cable shaped structure, also referred as to "stress ribbon structure" is one of the oldest structural type. Primitive bridge builders attempted to span distances wider than the length of an existing tree trunk by throwing a line across a ravine and tying it on both sides to a large rock or tree. In this simple and natural structural system, cables are stressed between the two abutments and serve as the walkway. In such a fashion, walkway surface and supporting cables - often from natural fibres - are one. The supporting cables - being their bending stiffness completely negligible - take the form of the funicular shape for the self-weight. 
Typically, the cables of modern stress ribbon structures consist in prestressing tendons or a system of at least two adjacent steel bands or cables laid out at the edges of the deck. However, a structure either made of only tendons or only steel bands without any supplementary stiffening means, would most probably not meet the requirements needed for its serviceability and its structural safety. If for instance such a structure was to be used as a bridge, it would deflect unacceptably under the action of concentrated loads. Furthermore, irrespective whether the structure was to be used as roof or as a bridge, aerodynamic instability would become a dangerous issue to reckon with.

There are a number of proven methods, which can be used to increase the bending stiffness of a cable-shaped structure, including adding weight or by using a secondary cable system, attached to the primary structure and pre-tensioned.

When a timber member, e.g. a curved glulam beam is used as a part of cable-shaped structure, it is normally not necessary to stiffen it by adding mass or pre-tensioned cables. In fact, timber members do possess inherent bending stiffness. Furthermore, timber has an excellent resistance to tensile stresses, especially in specific terms (i.e. the ratio between tensile strength and material density), which make it particularly adequate for cable-shaped structures.

One of the major challenge concerning cable-shaped timber systems is the design of adequate connections able to withstand the massive tension forces which typically arise when these structures are subjected to gravity loads as a consequence of their very low sag-to-span ratio. In the well-known cable-shaped timber bridge close to Essing, Germany, see Figure 30, the sag of each span was chosen so to limit the maximum tensile force in each of the $220 \times 650 \mathrm{~mm}^{2} \mathrm{glulam}$ beams to $4000 \mathrm{kN}$, which correspond to approximately $40 \%$ of their design tensile strength. The main glulam beams were prefabricated to lengths of 40-45 m and transported to site by road. This meant that each beam could be delivered in only 5 separate pieces. These pieces were connected onsite using large finger joints, which ensure that load is transferred from endgrain to end-grain in a very efficient fashion. The finger joints were tested in situ with loads $50 \%$ greater than the calculated serviceability loads in order to confirm their adequacy [12]. The total length of this timber bridge is approximately $190 \mathrm{~m}$, with the longest span of $73 \mathrm{~m}$.

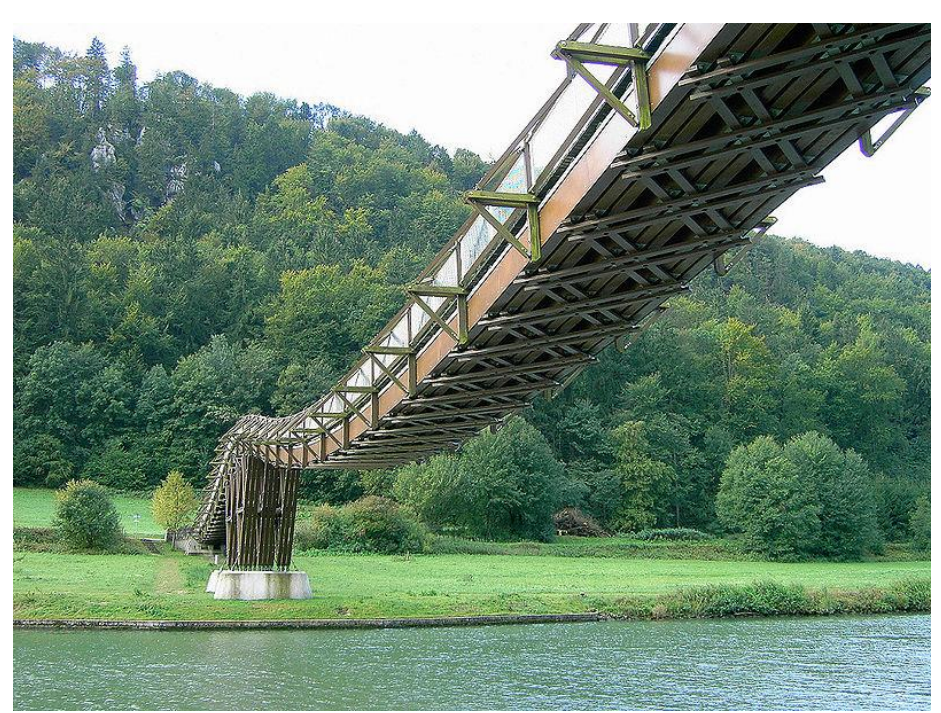

a)

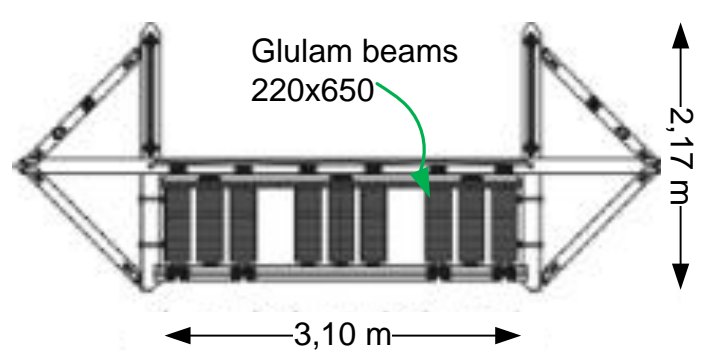

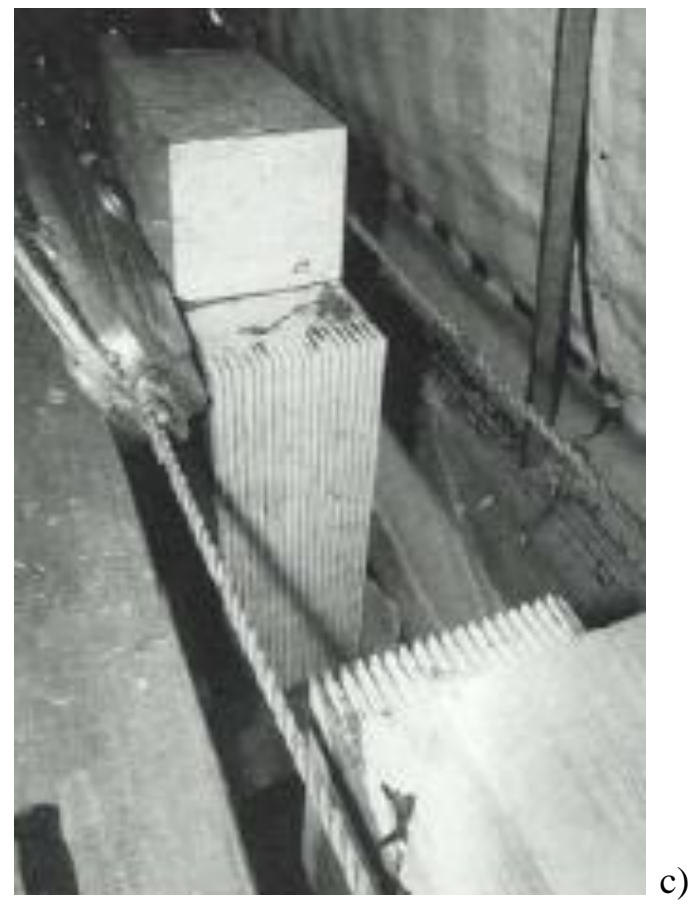

c) b)

Fig. 30: Cable-shaped timber bridge close to Essing, Germany. a) outlook of the bridge from below, with view of the lateral bracing. b) cross section of the bridge and c) beam's tension splice by means of a large finger joint, [11] and [12]. 
Figure 31 shows another application of cable-shaped structure, a "suspended roof" made of cross-laminate LVL (laminated veneer lumber).
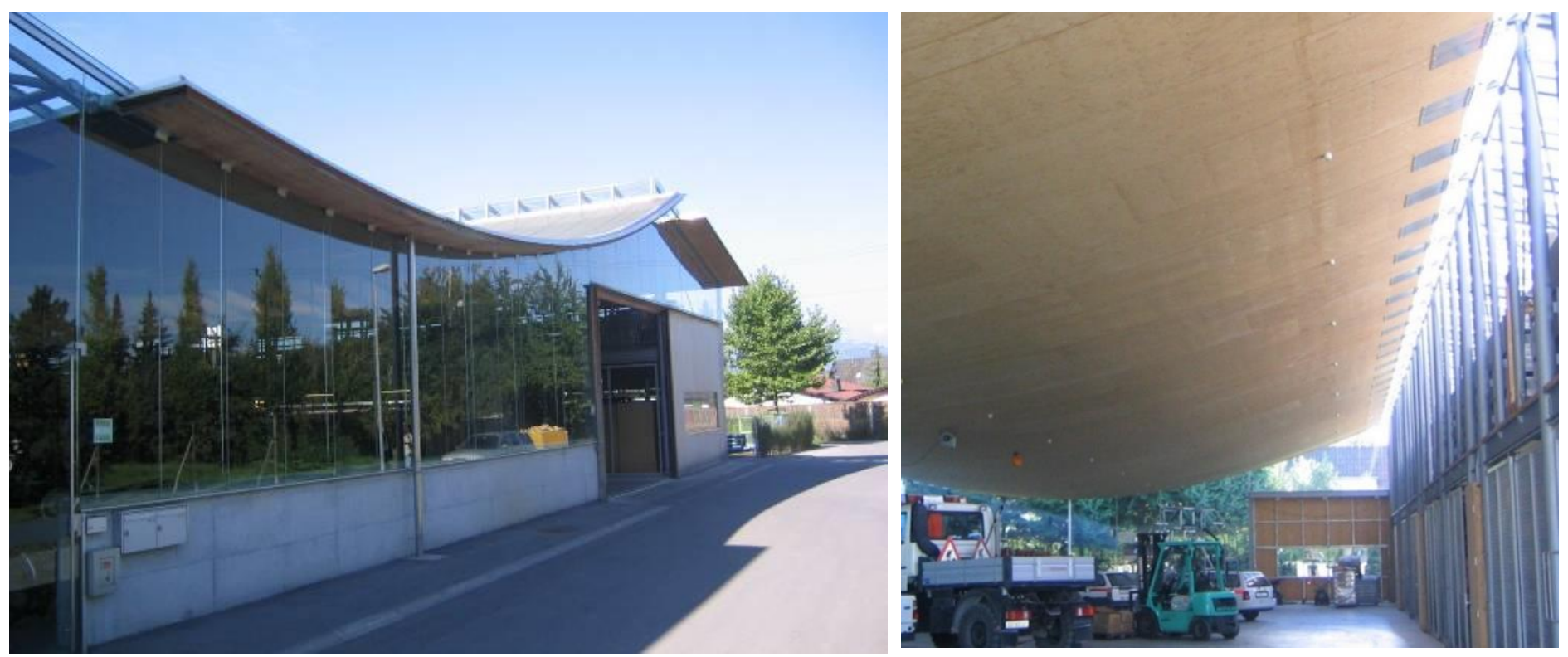

Fig. 31: Cable-shaped cross-laminated LVL roof in Switzerland. To the right, are visible the anchorages of the roof timber structure to the supporting steel structure by means of a number of nailed plate connections.

For spatial structures the assumption that most deformations and distribution of forces occur within a plane - as it is typically assumed in planar structures - cannot be made as these structures behave in three dimensions. Many structures such as grids, domes, barrel vaults, towers and cable nets belong to this category. However, typical timber spatial or space structures refer to structures made of an assemblage of linear members interconnected to each other in space, resisting loads applied at their connections or along their lengths.

Flat double or multi-layer grids, braced barrel vaults, braced domes, hyperbolic-paraboloids, and free-form configurations are all forms of spatial structures. Some spatial structures have positive Gaussian curvature (synclastic) such as domes, and some have negative Gaussian curvature (anticlastic) such as hyperbolic-paraboloids. Flat grids have zero Gaussian curvature.

Although both positive, negative and zero Gaussian curvature are fully feasible for space timber structures, domeshaped forms - such as that of the e Superior Dome in Marquette, Michigan, USA, shown in Figure 4 - are perhaps the most typically adopted timber spatial structure in real applications.

One of the earliest dome structure was the so called radial rib dome, see Figure 32. The load bearing part of this type of dome consists of a number of curved members arranged radially and hinged at their ends (meridian ribs) and - between these - a number of straight (or slightly curved) members arranged circumferentially (circular hoops). On the top of the dome, it is placed a compression ring, typically made of steel. The springing points of the meridian ribs are either connected to concrete foundations similar to those of Figure 19 (thus able to take the thrust from the ribs) or to a tension ring, typically made of pre-stressed concrete, at the bottom of the dome. Secondary members comprise diagonal bracing members and purlins. 


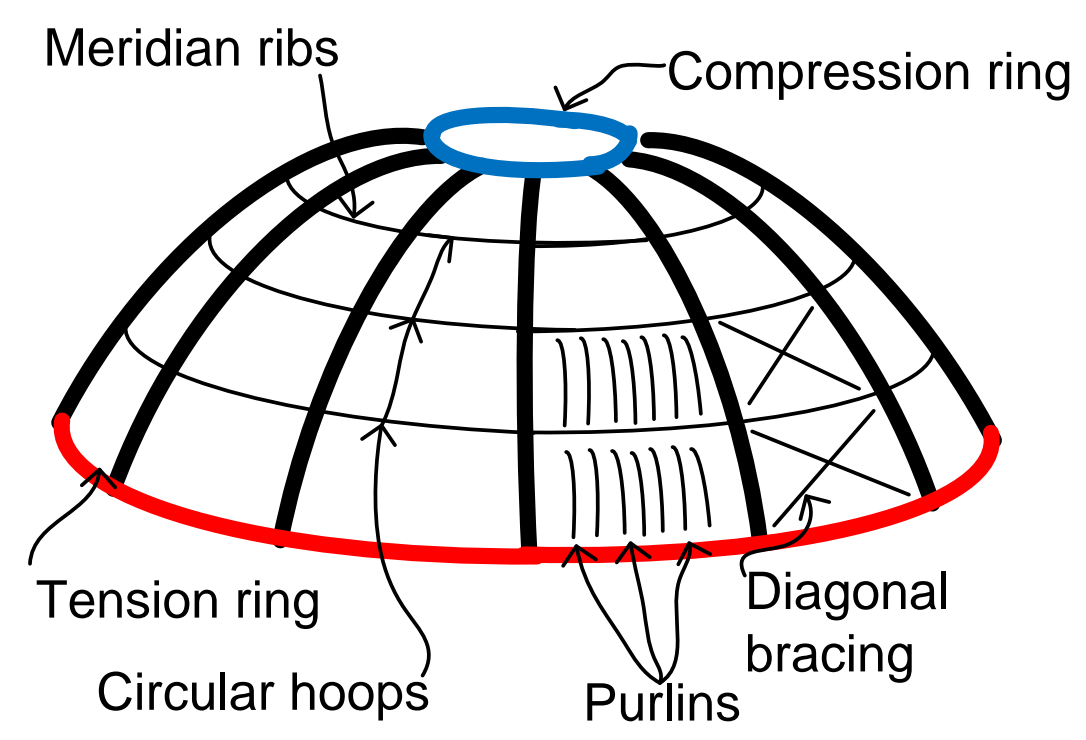

Fig. 32: Primary and secondary members of a typical radial rib dome structure. Meridian ribs, circular hoops and tension rings are typically made of wood. The remaining members are typically made of steel.

Often, modern timber domes are designed according to a geodesic geometry, see Figure 33. The geodesic dome was invented by R. Buckminster Fuller (1895-1983) in 1954. Geodesic domes are composed of triangles that are approximately equal, and such that the vertices of the triangles all lie on the surface of a sphere or a hemisphere. The triangular elements, have local rigidity and also distribute the structural stress throughout the geodesic sphere. Due do the triangulated geometry, geodesic dome structures do not need any additional bracing members. Geodesic domes are in general more economic than radial rib domes. Moreover, they are normally easier to erect and have superior load-carrying capacity than similar radial rib domes.

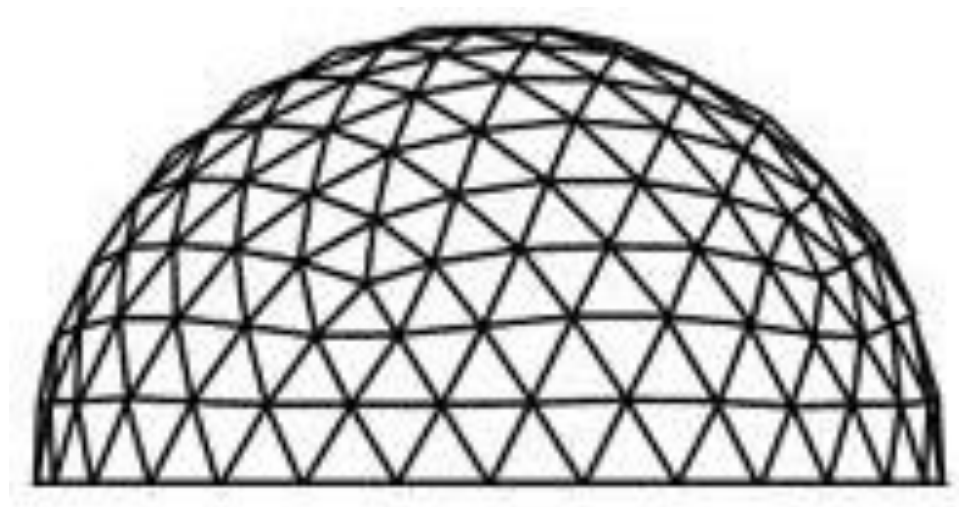

Fig. 33: Geodesic dome structure.

Recently, two glulam timber geodesic domes were built in Brindisi, Italy, in order to cover to large carbon stocks of an energy power plant. The preliminary activities at the construction site to create the first dome began in the month of December, 2013. The two carbon stock shelters were completed in the year 2015. Both domes are $143 \mathrm{~m}$ in diameter and $46 \mathrm{~m}$ in height, making them the largest of their type in Europe, see Figure 34. 


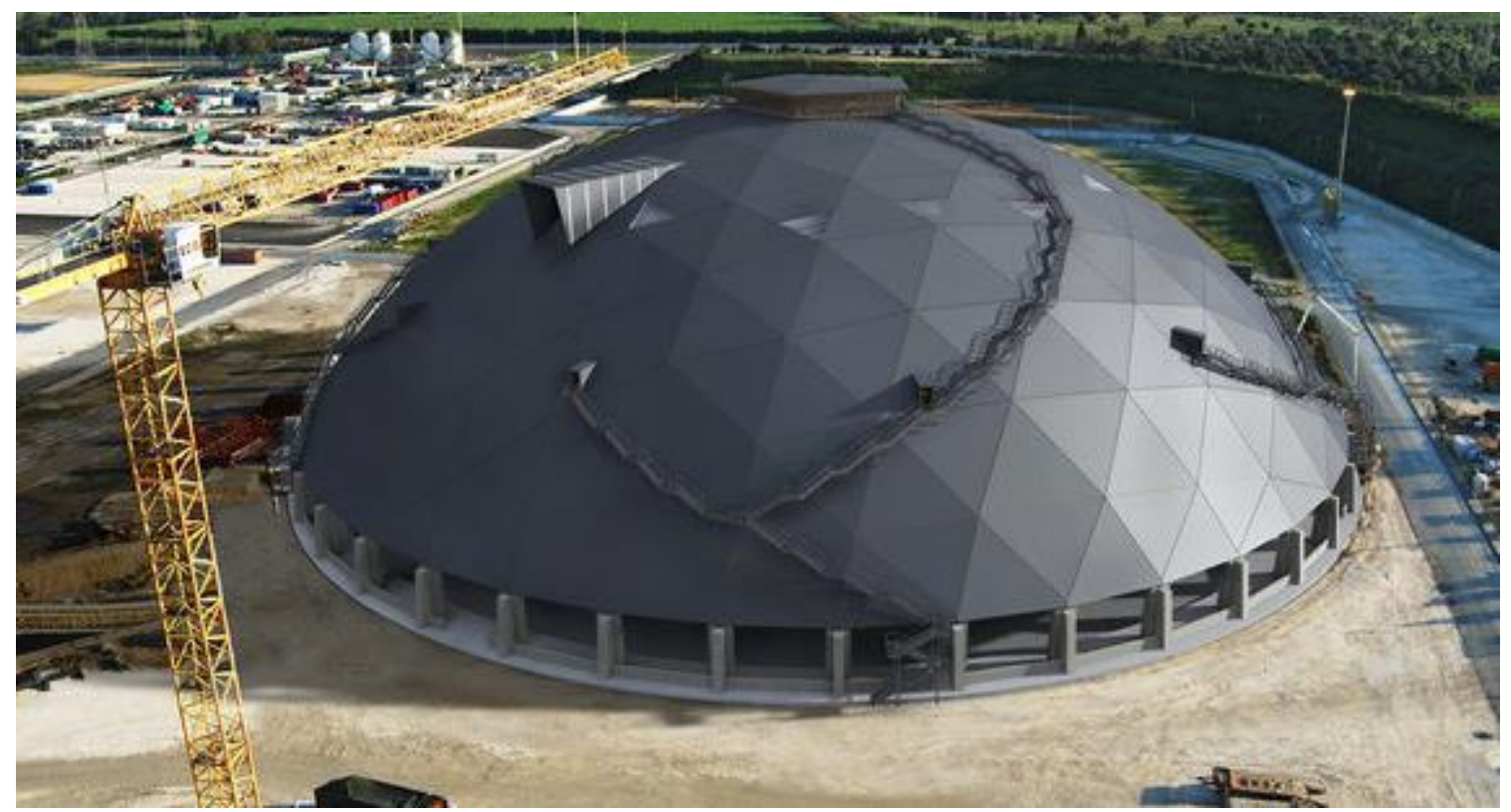

Fig. 34: One of the two geodesic dome structures in Brindisi, Italy. The span is $143 \mathrm{~m}$ and the height is $43 \mathrm{~m}$. Photo Rubner Holzbau.

The left part of Figure 35 shows one of the two geodesic dome in Brindisi during the construction phase. It is interesting to note that the erection occurred without the need of building a temporary supporting tower in the centre of the dome area, which is typical for radial rib dome structures. This considerably reduce the construction costs. In order to allow for this type of construction method, special joints were designed for the nodes of the dome. The joints, which consists of steel plates and inclined self-tapping screws, are designed to resist bending moments and shear forces that arise during the construction phase, when the members of the triangulated dome are cantilevering out, see the right-hand side of Figure 35.

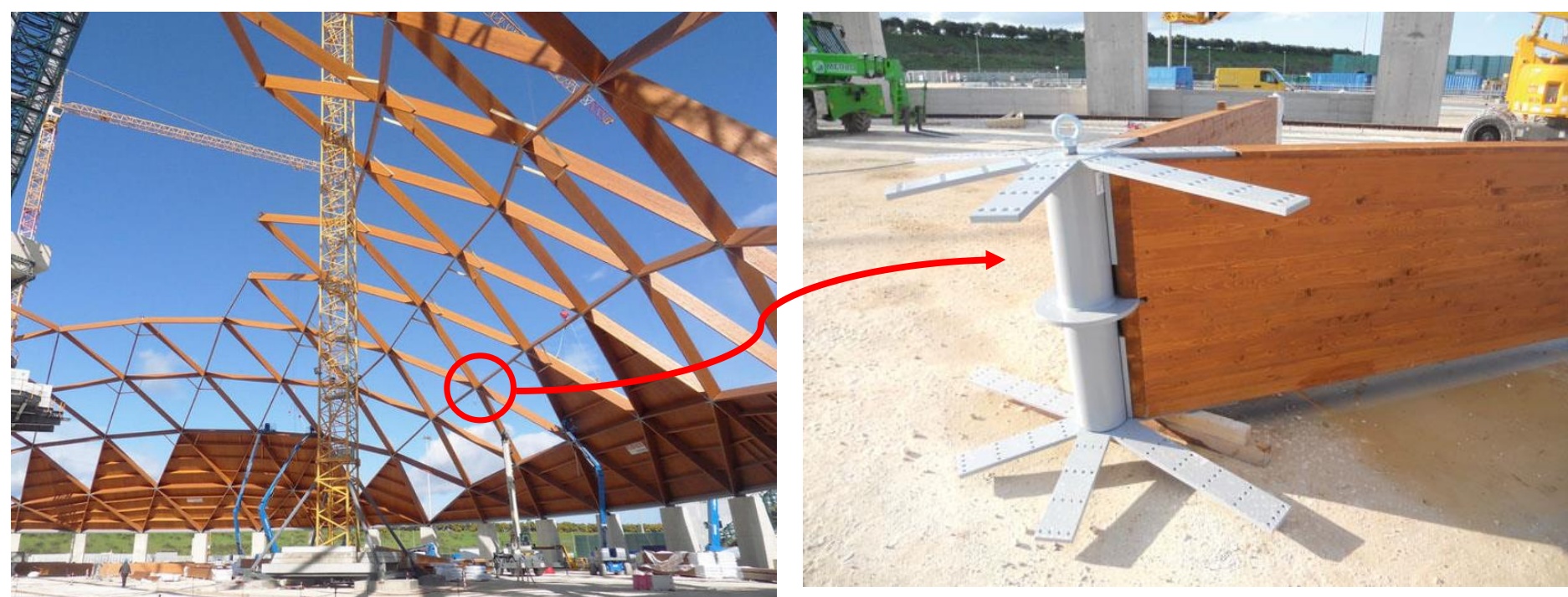

Fig. 35: Left: One of the two geodesic dome structures in Brindisi, Italy during erection. Right: a detail of a node of the dome.Photo Rubner Holzbau.

Nodes play an important role in large timber structures, in particular in dome structures. Simple welded or "plug-in" connections which are typical in steel structures are normally not possible with timber. It is necessary, therefore, to reduce as much as possible the number of nodes, to create connections which are very adaptable and that allow for an easy 
erection of the structure. Figure 36 shows two examples of joints that have been used as nodes of space structures and that fulfil the above requirements.
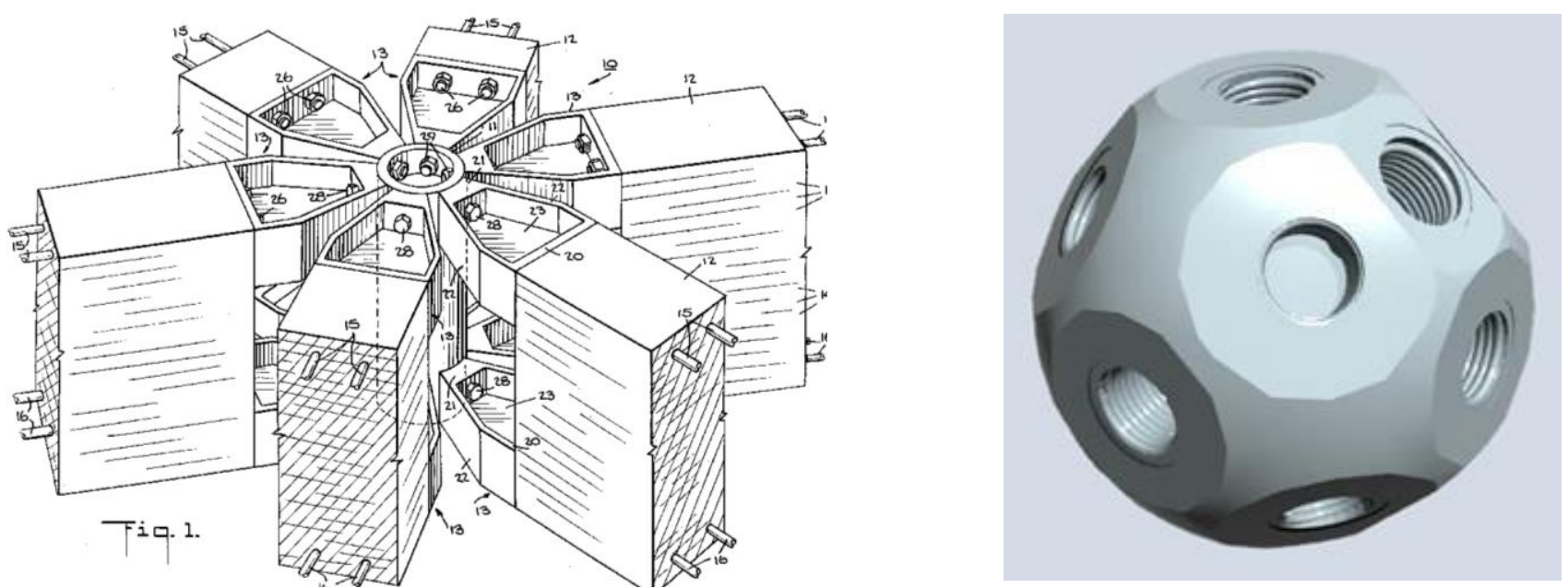

Fig. 36: Two examples of nodes for spatial timber structures. Left: Connector for a timber structural member, Patent: US 4484430 A.

Right: a MERO node.

\section{Conclusions}

Timber's excellent mechanical properties where thoroughly discussed, along with timber's suitability in larg-span structure applications.

Both traditional and innovative structural shapes typically used in large-span timber structures were discussed with emphasis on planar structures. A short explanation of spatial structures was also presented.

Stability issues concerned to slender timber structures were debated. Examples of connections that can be used in large-spans structures were introduced.

Finally, a number of existing large span-structures were presented, along with information concerning their geometry and structural behaviour.

\section{References}

[1] R. Crocetti, "Timber bridges: general issues, with particular emphasis on Swedish typologies," in Internationales Holzbau-Forum IHF 2014, Garmisch, Germany, 2014.

[2] F. Griggs, "The Colossus of the Schuylkill River," In Articles, Historic Structures, 2014.

[3] The British glued laminated timber association (GLTA) [Online]. Available: http://www.glulam.co.uk/.

[4] A. Fayerre and J-B. Journot, "Timber trussed arch for long span," Master's Thesis in the International Master's Programme in Structural Engineering, Department of Civil and Environmental Engineering, Chalmers University of Technology, Göteborg, Sweden, 2005.

[5] B. N. Sandaker, On Span and Space: Exploring Structures in Architecture. Routledge: Taylor \& Francis Group, 2008.

[6] J. E. Gordon, Structures, or why things don't fall down. London: Penguin books, 1991.

[7] D. L. Shoedek, Structures, 5th Ed. Prentice Hall, 2004.

[8] B. Andersson and G. Larsson, "Verification of buckling analysis for Glulam arches," Master's thesis, Division of structural Mechanics, Lund University, 2014.

[9] Eurocode 5, "Design regulations for timber structures," EN 1995-1-1.

[10] R. Crocetti, et al., Glulam handbook. Swedish Wood, to be published in April 2016.

[11] R. J. Dietrich, "Six Timber Bridges of Special Interest," in International conference on timber bridges ICTB 2010, Lillehammer, Norway, 2010.

[12] H. Brüninghoff, “The Essing Timber Bridge, Germany," Structural Engineering International, vol. 3, no. $2,1993$. 